The author(s) shown below used Federal funds provided by the U.S. Department of Justice and prepared the following final report:

Document Title: Assessing the Offending Activity of Criminal Domestic Violence Suspects: Offense Specialization, Escalation, and De-Escalation Evidence from the Spouse Assault Replication Program

Author(s): Alex R. Piquero, Robert Brame, Jeffrey Fagan, Terrie E. Moffitt

Document No.: 212298

Date Received: December 2005

Award Number: 2004-IJ-CX-0013

This report has not been published by the U.S. Department of Justice. To provide better customer service, NCJRS has made this Federallyfunded grant final report available electronically in addition to traditional paper copies.

Opinions or points of view expressed are those of the author(s) and do not necessarily reflect the official position or policies of the U.S. Department of Justice. 
Assessing the Offending Activity of Criminal Domestic Violence Suspects:

Offense Specialization, Escalation, and De-Escalation Evidence from the Spouse Assault Replication Program

\author{
Alex R. Piquero \\ University of Florida \\ Robert Brame \\ University of South Carolina \\ Jeffrey Fagan \\ Columbia University \\ Terrie E. Moffitt
}

University of Wisconsin \& Institute of Psychiatry, Kings College London

FINAL REPORT SUBMITTED TO NATIONAL INSTITUTE OF JUSTICE 
Table of Contents

Section

Proposal Abstract 3

Introduction 4

Theoretical Context $\quad 7$

Specialization in Domestic Violence 9

Escalation and De-Escalation in Criminal Domestic Violence 11

Current Study $\quad 13$

$\begin{array}{ll}\text { Data } & 14\end{array}$

Analytic Plan $\quad 18$

Specialization Analysis Results $\quad 26$

-Charlotte Analysis 26

-Colorado Springs Analysis $\quad 27$

-Milwaukee Analysis $\quad 29$

-Omaha Analysis $\quad 30$

Summary of Specialization Analysis Results 31

Escalation and De-Escalation Analysis Results 32

-Charlotte Analysis $\quad 32$

-Miami-Dade Analysis $\quad 36$

-Milwaukee Analysis $\quad 39$

-Omaha Analysis 41

Summary of Escalation and De-Escalation Analysis Results $\quad 43$

Discussion 44

References $\quad 50$

List of Tables $\quad 54$

List of Figures $\quad 55$

Tables (1-3) 56

Figures (1-14) 59 


\section{PROPOSAL ABSTRACT}

\section{Research Goals and Objectives:}

Two key dimensions of the criminal career paradigm include specialization and escalation. Although these topics have generated theoretical and empirical debate in the criminal careers area, this line of research has not been integrated into the study of domestic violence, and remains limited in several ways. In this project, we build upon these limitations and explore, using both official records and victim interviews, issues related to specialization and escalation using data from the Spouse Abuse Replication Program (SARP). Specifically, we examine (1) the extent to which offenders participating in the SARP exhibit a specialized proclivity to violence; and (2) tendencies of these individuals to escalate or de-escalate the severity of their attacks against the same victim.

\section{Results}

First, regarding the extent to which criminal domestic violence offenders specialize in violent offending, our analysis reveals that the majority of domestic violence offenders with prior official criminal records have been involved in non-violent forms of criminal behavior in addition to domestic violence. Second, regarding the question of whether the severity of an offender's attacks against the same victim increase, decrease, or stay about the same over the course of a well-defined follow-up period, our analysis identifies groups of escalators and de-escalators as well as individuals who engage in stable low-level aggression and stable high-level aggression. Future research directions are identified.

Keywords: intimate partner violence; criminal careers; specialization; escalation. 


\section{Introduction}

After a long period of neglect, intimate partner violence has become an increasingly prominent research and policy topic over the past twenty-five years (Fagan and Browne, 1994:116; Chalk and King, 1998; Dobash and Dobash, 1992; Koss et al., 1994). ${ }^{1}$ National surveys estimate that an act of physical violence is committed by a family member in nearly half of all homes during an average 12-month period in the United States (Gelles and Straus, 1988). Minimum estimates from these surveys indicate that acts of physical aggression between spouses occur in one of six homes each year (Fagan and Browne, 1994). Two other recent large-scale surveys also provide a glimpse of the problem of intimate partner violence. For example, data from the National Crime Victimization Survey (NCVS) indicate that the number of female victims of intimate violence declined from 1993 to 1998 (Rennison, 2000). The National Violence Against Women Survey (Tjaden and Thoennes, 2000), based on a telephone survey of a representative sample of 8,000 U.S. men and 8,000 U.S. women, surveyed individuals about their experiences as victims of various forms of violence, including intimate partner violence. Amidst the many important findings, three in particular stand out for present purposes. First, intimate partner violence is pervasive. Twenty-five (25\%) percent of the women and $7.6 \%$ of men said they were raped and/or physically assaulted by a current or former spouse, cohabitating partner, or date at some point in their lifetime. Second, violence against women by intimates is often accompanied by emotionally

\footnotetext{
${ }^{1}$ We follow Fagan and Browne (1994:119) and consider domestic violence generally, but use the label 'intimate partner violence' throughout to include “the terms wife assault, marital violence, spouse abuse, and spouse assault.”
} 
This document is a research report submitted to the U.S. Department of Justice. This report has not

been published by the Department. Opinions or points of view expressed are those of the author(s)

and do not necessarily reflect the official position or policies of the U.S. Department of Justice.

abusive and controlling behavior. Third, females more than males, experience chronic and injurious physical assault at the hands of intimate partners.

Although considerable effort has been devoted to research on intimate partner violence in recent years, knowledge about the criminal careers of domestic violence offenders remains limited largely because researchers interested in partner and domestic violence have tended to operate under the assumption that partner/domestic batterers specialize in that particular offense to the neglect of all others, and that many batterers escalate in their offending activity from less to more serious crimes. Until recently, these issues have remained virtually unexplored because of the "bifurcation between the fields of domestic violence research and criminology” (Moffitt et al., 2000:201; Fagan and Browne, 1994).

A criminal career refers to an individual's crime commission experiences arrayed over the life span (Blumstein, Cohen, Roth, and Visher, 1986). A great deal of research on criminal careers has emphasized distinctions between those who become involved in criminal offending in comparison to those who do not and the frequency of crimes and the duration of the criminal career among those who offend (Piquero, Farrington, and Blumstein, 2003). Researchers have also asked whether offenders exhibit generalized or specialized careers and whether the seriousness of offenses in those careers progresses in an orderly fashion (Elliott, 1994; Le Blanc and Fréchette, 1989). The preponderance of studies show that offending behavior tends to be a generalized enterprise with relatively limited evidence of offense specialization (Piquero et al., 2003). Evidence on the escalation and de-escalation of offense seriousness over the course of offending careers is less abundant but suggests that escalation tendencies are most pronounced for juvenile 
This document is a research report submitted to the U.S. Department of Justice. This report has not

been published by the Department. Opinions or points of view expressed are those of the author(s)

and do not necessarily reflect the official position or policies of the U.S. Department of Justice.

offenders and de-escalation tendencies are more pronounced for adult offenders

(Blumstein et al., 1988; Rojek and Erickson, 1982).

While research on the prevalence and frequency of intimate partner violence and victimization has evolved considerably over the past two decades, little progress has been made in understanding other features of the criminal careers of domestic violence offenders such as the mix of offenses in which they are involved and the progression of offense seriousness against the people they victimize. Limited research indicates that partner abusers do not specialize but engage in violence against non-partners as well as a variety of nonviolent crimes (Fagan and Wexler, 1987), and that careers in marital and stranger violence tend to converge as violence in either domain becomes more frequent and serious (Fagan and Browne, 1994:253).

There have been few efforts to integrate the empirical literature on aggression within families with other perspectives on violence, and to the extent that there is significant overlap, the establishment of linkages between intimate partner violence and criminal behavior more generally remains a “critical gap” (Fagan and Browne, 1994:253). Moreover, since most theory and research into partner abuse has remained separate from theory and research into crime, attention from questions about associations between partner abuse and crime have been diverted (Moffitt et al., 2000).

In this report, we integrate the study of the criminal career dimensions of specialization and escalation into the study of domestic violence. Specifically, we address this gap by using data on the offending activities of spouse assault suspects participating in several of the Spouse Assault Replication Program (SARP) sites to better 
This document is a research report submitted to the U.S. Department of Justice. This report has not

been published by the Department. Opinions or points of view expressed are those of the author(s)

and do not necessarily reflect the official position or policies of the U.S. Department of Justice.

document: (1) the extent to which these individuals exhibit a specialized proclivity to violence; and (2) tendencies of these individuals to escalate or de-escalate the severity of their attacks against the same victim. ${ }^{2}$ Unlike other criminal career/domestic violence studies, an important feature of our analysis is that it integrates data from two distinct reporting sources, i.e., official records and self-report interviews.

\section{THEORETICAL CONTEXT}

The extent to which there is a common explanation of crime that applies to all offenders is a contentious issue. Gottfredson and Hirschi (1990) argue that all criminal, deviant, and analogous acts can be attributed to variations in self-control and available opportunities. Their theory advocates a general/static viewpoint of criminal behavior which presumes that there is a general cause of crime for all offenders and that, once the causal process has played out, change is unlikely. Sampson and Laub (1993) offer an important variation to this 'common explanation' theory. To these scholars, crime can be understood as the product of informal social controls such as the family, school, marriage, employment and so on. This approach, characterized as a general/dynamic viewpoint, attributes importance to change.

Although both sets of scholars agree on the generality assumption, developmentalists relax the assumption (of one trajectory for all offenders) thereby adding further complexity. Developmentalists are friendly to the notion that both persistent individual differences and changing life circumstances are related to involvement in crime, and that these factors affect different groups of offenders in

\footnotetext{
${ }^{2}$ The escalation portion of this study is not about switching partners or about switching from domestic partners to strangers, or continuity of domestic violence across different partners. Instead, it is about
} 
This document is a research report submitted to the U.S. Department of Justice. This report has not

been published by the Department. Opinions or points of view expressed are those of the author(s)

and do not necessarily reflect the official position or policies of the U.S. Department of Justice.

different ways. The developmental view grants that there are different kinds of offenders, each possessing a unique sequelae to crime, as well as a different criminal repertoire. As such, developmentalists contend that treating all offenders as emanating from the same population would be inconsistent with research documenting offender heterogeneity (D’Unger et al., 1998; Nagin and Land, 1993).

Although several developmental theories exist, one prominent example is Moffitt's (1993) developmental taxonomy. She rejects the assumption that there is a general theory of crime and argues for the existence of two distinct groups of offenders. One of these offender groups, life-course-persistent, is characterized by continuity in offending, and the other group, adolescence-limited, is characterized by change in offending. Life-course-persistent offenders originate as a result of the interaction between neuropsychological deficits and deficient familial and neighborhood environments. These individuals are typically born into families who are ill-prepared to perform effective socialization. As a result of ineffective socialization, life-coursepersisters fail in their family life, their school work, and all sorts of interpersonal relationships. Since they never learn to control their antisocial proclivities, they act impulsively as children, adolescents, and adults. For this group of offenders, continuity is the modal behavior, and change is unlikely. The criminal repertoire of life-coursepersisters is believed to include all sorts of criminal acts, including violence. On the other hand, adolescence-limited offenders begin offending in adolescence as a function of the perceived maturity gap and the peer social context of adolescence. Since adolescence-limiteds do not suffer from life-course-persistent type risk factors, as 
This document is a research report submitted to the U.S. Department of Justice. This report has not

been published by the Department. Opinions or points of view expressed are those of the author(s)

and do not necessarily reflect the official position or policies of the U.S. Department of Justice.

adulthood ensues they are likely to embrace their prosocial tendencies and skills and desist. For this group, change is modal. The criminal repertoire of adolescence-limiteds is believed to include mainly status and nonviolent delinquent acts.

The debate between developmental and general theories hinges on differences, if any, between individuals in their patterns of offending and in the covariates that reflect possible underlying causal forces (McDermott and Nagin, 2001). Related to this debate is the extent to which offenders specialize in offending. Interestingly, the theoretical models discussed above make markedly different predictions regarding specialization. For both Gottfredson and Hirschi and Sampson and Laub, versatility in offending is the norm; in other words, both of these general theories claim that offenders rarely (if ever) specialize. For example, Gottfredson and Hirschi (1990:91) contend that "within the domain of crime...there will be much versatility among offenders in the criminal acts in which they engage.” Similarly, Sampson and Laub (1993:56) contend that “[because of] the low level of specialization in specific crimes committed by the Glueck men...[our] theoretical framework does not make crime-specific predictions.” Recently, Laub and Sampson (2001:63) noted that their "life history narratives [suggest] no major differences in the process of desistance for non-violent and violent juvenile offenders.” However, developmentalists anticipate both specialized and generalized patterns of criminal activity. In Moffitt's scheme, life-course-persisters engage in both nonviolent and violent crimes, while adolescence-limiteds concentrate their crime in the nonviolent domain.

\section{Specialization in Criminal Domestic Violence}

Despite evidence suggesting that criminal violence frequently occurs between 
This document is a research report submitted to the U.S. Department of Justice. This report has not

been published by the Department. Opinions or points of view expressed are those of the author(s)

and do not necessarily reflect the official position or policies of the U.S. Department of Justice.

family members as well as between acquaintances and strangers (Bureau of Justice

Statistics, 2002: Table 34), researchers continue to study these patterns separately leaving many important questions unanswered. For example, is family violence a part of a generalized pattern of violence? If so, can we expect its career parameters and phases to parallel other types of violence patterns (Fagan and Browne, 1994:250)? Is a special theory needed to account for partner violence? For example, some scholars believe that intimate violence requires its own specific theory (Gelles and Straus, 1979). Or are domestic batterers also generalists in that they engage in more general forms of violence, as well as different types of non-violent criminal activity (Farrington, 1991; Gottfredson and Hirschi, 1990; Piquero, 2000)?

Although some research has examined the intersection of family and stranger violence (Shields et al., 1988; Fagan et al., 1983), only one study has attempted to rigorously examine this issue. Using data from the Dunedin Multidisciplinary Health and Development Study, a longitudinal investigation of the health, development, and behavior of a cohort of consecutive births $(n=1,037)$ between April 1, 1972 and March 31, 1973 in Dunedin, New Zealand, Moffitt et al. (2000) used Confirmatory Factor Analysis to study the relation between partner abuse and general crime. Three key findings emanate from their study. First, partner abuse and general crime represented different constructs that were moderately related. Second, group comparisons showed that many, but not all, partner abusers also engaged in violence against nonintimates. Third, personality analyses showed that partner abuse and general crime shared a strong propensity from a trait called negative emotionality. 
This document is a research report submitted to the U.S. Department of Justice. This report has not

been published by the Department. Opinions or points of view expressed are those of the author(s)

and do not necessarily reflect the official position or policies of the U.S. Department of Justice.

In sum, there are too few studies on the specialization of domestic violence offenders to draw any firm conclusions.

\section{Escalation and De-Escalation in Criminal Domestic Violence}

There is some evidence that criminal careers in intimate partner violence follow patterns similar to criminal careers in stranger violence or property crime, with discernible patterns of initiation, escalation, continuity, and desistance (Fagan and Browne, 1994:151). Herein, we focus on escalation, or "the tendency for offenders to move to more serious offense types as offending continues” (Blumstein et al., 1986:84) and its conceptual counterweight, de-escalation.

Only a handful of studies have examined the nature of escalation within intimate partner violence. Using data gathered primarily from samples of female victims of intimate partner (marital) violence, some research indicates that such violence escalates in frequency and severity over time (Walker, 1984; Pagelow, 1994; Fagan et al., 1984). Feld and Straus (1989) used panel data from the 1985 National Family Violence Survey and a second wave collected in 1986 to examine patterns of continuity and discontinuity in family violence. They found that such patterns varied by the severity of violence in the first wave. Although more than half of the sample continued their participation in severe violence, ten percent reduced the severity of their violence, and thirty-three percent reported no violence during the second year; however, minor assaults in 1985 were associated with more serious assaults over the second year, suggesting patterns of escalation.

In addition, Johnson (1995:286) argues that it may be misleading to discuss 
This document is a research report submitted to the U.S. Department of Justice. This report has not

been published by the Department. Opinions or points of view expressed are those of the author(s)

and do not necessarily reflect the official position or policies of the U.S. Department of Justice.

patterns of escalation in domestic violence for the population as a whole. For families experiencing what Johnson refers to as "common couple violence" there is apparently very little evidence of escalation. On the other hand, victims of more serious and persistent violence-what Johnson (1995) calls “patriarchal terrorism”-apparently experience the brunt of the escalation problem. This research suggests that patterns of escalation may differ in important ways across the population. Johnson's exploratory research in this area implies that it may be necessary to disaggregate patterns of offense mix and escalation.

In sum, the conclusion drawn from this research seems to support varied career trajectories of escalation in intimate partner violence, with some research indicating that intimate partner violence may be episodic, with lengthy intervals of nonviolence interrupted by shorter periods of intensive violence (Walker, 1984; Fagan, 1989). At the same time, several limitations to these prior escalation studies prohibit firm conclusions on the extent to which intimate partner violence escalates over time. First, most of these studies have not examined the extent to which misdemeanor domestic violence escalates over time within the same dyad. Second, prior research has tended to employ outcome data from one source; that is, researchers have employed either official records or victim self-reports. By employing data from both official records and victim interviews, our estimates of criminal career patterns during the follow-up period will not be subject to biases arising from suspect interviews and/or drop-out. Third, prior efforts have not established a methodological approach, one that can be employed and compared across studies, that allows researchers to characterize escalation in a statistical fashion. Finally, 
This document is a research report submitted to the U.S. Department of Justice. This report has not

been published by the Department. Opinions or points of view expressed are those of the author(s)

and do not necessarily reflect the official position or policies of the U.S. Department of Justice.

the issue of escalation has yet to be addressed with data from the SARP within the methodological context within which we operate.

\section{Current Study}

In this study, we build upon prior research and follow Fagan and Browne’s (1994:253) suggestion that researchers integrate issues related to both family violence and criminal careers. Specifically, using data from the SARP we examine: (1) the extent to which offenders exhibit a specialized proclivity toward violence (e.g., specialization), and (2) the extent to which attack severity escalates, de-escalates, or stays about the same over time (e.g., escalation). In particular, we believe it is useful to document the mix of offenses that occur within intimate relationships and to investigate whether offenders will exhibit escalation or de-escalation in the seriousness of their offenses against the same victim. Distinctions among escalators and non-escalators may prove useful in guiding development of theoretical models designed to account for domestic violence (Fagan and Browne, 1994). The larger issue is that there may be heterogeneity among domestic batterers such that a typology of domestic batterers is relevant (Holtzworth-Munroe et al., 2000) and an investigation into the kinds of characteristics that help un-pack the heterogeneity within domestic batterers will advance knowledge in this area (Johnson, 1995).

Aside from its theoretical implications, the extent to which offenders escalate into more serious crimes over time may prove useful for informing policy deliberations. To the extent that careers in intimate partner violence escalate in seriousness with offenders moving to increasingly more serious intimate partner violence as they proceed from one 
This document is a research report submitted to the U.S. Department of Justice. This report has not

been published by the Department. Opinions or points of view expressed are those of the author(s)

and do not necessarily reflect the official position or policies of the U.S. Department of Justice.

arrest to another, then crime control strategies that are effective in interrupting the normal

progress of martial violence careers would be especially beneficial in reducing

subsequent serious crimes (Blumstein et al., 1988). We view this research as a useful

step in strengthening the knowledge base necessary for sound development of theory and

policy.

Data

To examine these questions, we use data from the Spouse Assault Replication Program (SARP). The SARP was originally designed to replicate the Minneapolis domestic violence experiment conducted by Sherman and Berk (1984). In the Minneapolis study ( $\mathrm{n}=314)$, Sherman and Berk compared repeat domestic violence rates for cases where the offender was arrested to cases where the police responded informally in one of two ways, advisement or separation. In the advisement condition, the police left the home only after advising the couple to calm down, while in the separation condition the police ordered the suspect to leave the home for eight hours. The project only applied to simple (misdemeanor) domestic assaults where both the suspect and the victim were present when the police arrived (Sherman and Berk, 1984). ${ }^{3}$

The results of the Minneapolis study indicated that arresting domestic violence suspects led to a lower risk of repeat domestic violence, and this was the case in both

\footnotetext{
${ }^{3}$ According to Sherman (1992:272): "The design called for each officer to carry a pad of report forms, color coded for the three different police responses. Each time the officers encountered a situation that fit the experiment's criteria, they were to take whatever action was indicated by the report form on the top of the pad. The forms were numbered and arranged for each officer in an order determined by the lottery. The consistency of the lottery assignment was to be monitored by research staff observers riding on patrol for a sample of evenings. After a police action was taken at the scene of a domestic violence incident, the officer was to fill out a brief report and give it to the research staff for follow-up. As a further check on the lottery process, the staff logged in the reports in the order in which they were received and made sure that the sequence corresponded to the original assignment of responses."
} 
official and victim interviews. More specifically, arrest and a night in jail cut in half the risk of repeat violence against the same victim over a six-month follow-up period (Sherman, 1992:2). Because the study relied on randomized treatment assignment, its internal validity was strong. ${ }^{4}$

To examine the external validity of this result, in 1986 the National Institute of Justice funded replications of the Minneapolis experiment in six other cities in geographically diverse regions around the United States including Atlanta, Charlotte ( $n=650)$, Colorado Springs $(n=1,658)$, Miami-Dade $(n=907)$, Milwaukee $(n=1,200)$, and Omaha ( $\mathrm{n}=330)$, which also contained a second experiment that tested the issuance of arrest warrants in cases in which suspects had left the home before police arrived (i.e., the “offender-absent” experiment) (Maxwell, Garner, and Fagan, 2002; Sherman, 1992:15). The Atlanta project was never completed but the projects in the other sites were completed and we use data from all of them in our study. The implementation of the SARP studies and interpretation of the SARP findings have been described in detail by Garner, Fagan, and Maxwell (1995) and Maxwell et al. (2002). We provide some further information here.

There were a number of important differences across the replication sites. First, only Omaha’s offender-present experiment actually replicated the original Minneapolis

\footnotetext{
${ }^{4}$ As with any experiment, there were some difficulties in Minneapolis. According to Sherman (1992:12) many of the officers occasionally failed to follow fully the experimental design for a variety of reasons including forgetfulness, misunderstanding about whether the experiment applied in certain situations, or officers dropping out of the experiment. Also, there were difficulties associated with getting the victims to grant follow-up interviews to report any repeat violence. Treatment-designed and treatment delivered was highest in the arrest condition (98.9\%), and fairly high in the advise (77.8\%) and separate (72.8\%) conditions (Sherman, 1992:274). Because arrest became a fallback position, the 'more difficult' offenders who did not comply with the other conditions were arrested, thus biasing against finding a deterrent effect of arrest (see Sherman, 1992:275).
} 
This document is a research report submitted to the U.S. Department of Justice. This report has not

been published by the Department. Opinions or points of view expressed are those of the author(s)

and do not necessarily reflect the official position or policies of the U.S. Department of Justice.

research design; the other experiments, while replicating the random arrest/no-arrest assignment component of Minneapolis, tested different treatments or combinations of treatments (Sherman, 1992:15). Second, the replication experiments forced the officer to call a dispatcher for a random assignment of police response. In Minneapolis, the officer knew what the assignment would be because of the colored paper. Third, there were alternative treatments included. For example, in Milwaukee the mediation and separation components of the original Minneapolis experiment were omitted in favor of comparing a standard verbal warning to two different lengths of time in custody after arrest (three versus twelve hours) (Sherman, 1992:16). In Colorado Springs, arrest was compared to two alternatives: immediate professional counseling at police headquarters and issuance of an emergency protection order formally barring the suspect from the premises (Sherman, 1992:16). In Charlotte, arrest was compared to either mediation or separation and to issuing a ticket at the scene requiring the suspect's presence in court on a future date, while in Miami-Dade, arrest was compared to no-arrest, both with and without follow-up counseling by a specially trained police unit that visited the home a few days after the incident (Sherman, 1992:16). Fourth, the replication sites were comprised of very different ‘types’ of samples. For example, married couples were more common in Miami (79\%) and Colorado Springs (69\%), while uncommon in Milwaukee (30\%) and Minneapolis (35\%). Black suspects were most common in Milwaukee (75\%) and Charlotte (70\%), and least common in Colorado Springs (31\%). Unemployment of suspects was most prevalent in Minneapolis (60\%) and Milwaukee (47\%). High-crime area samples were common in Minneapolis and Milwaukee. And finally, sample sizes 
This document is a research report submitted to the U.S. Department of Justice. This report has not

been published by the Department. Opinions or points of view expressed are those of the author(s)

and do not necessarily reflect the official position or policies of the U.S. Department of Justice.

varied from a low of 314 in Minneapolis to a high of 1,658 in Colorado Springs. Fifth, the replication findings were mixed. For example, in three cities (Minneapolis, MiamiDade, and Colorado Springs) a deterrent effect was observed while in the three other cities (Milwaukee, Omaha, and Charlotte), arrest backfired causing an escalation effect. Additionally, arrest seemed to work different depending on the constellation of individual characteristics. Specifically, arrest deterred employed suspects in Omaha, Milwaukee, and Colorado Springs, but backfired (led to escalation) in those three cities for unemployed suspects. Additionally, in three cities (Omaha, Charlotte, and Milwaukee) there was a six-month deterrent effect in the official records, but this deterrent effect decayed over time such that between six- and twelve-months, the official measures in these three cities provided evidence of escalation. Finally, the offender-absent experiment in Omaha provided very strong evidence of a deterrence effect for warrant group compared to the no-warrant group.

Two particular aspects of the SARP data are important for our purposes. First, the SARP data contain information on arrest activity prior to the incident in which the offender entered the experiment (i.e., the presenting incident). This information takes the form of frequency distributions but it does divide the types of offenses into property, violent, and other crimes. These data will allow us to examine whether individuals entering the experiments exhibit specialization in violence. Second, the data contain detailed information from victim interviews on the nature of the violence occurring at the presenting incident as well as the nature of the violence occurring at subsequent points in time after the presenting incident. With these data, we will examine the extent to which the severity of offenders' attacks against the same victim increases, decreases, or stays 
This document is a research report submitted to the U.S. Department of Justice. This report has not

been published by the Department. Opinions or points of view expressed are those of the author(s)

and do not necessarily reflect the official position or policies of the U.S. Department of Justice.

about the same. Specifically, we will use data from the SARP to answer two questions:

(1) to what extent do individual domestic violence suspects exhibit specialization in violent offending behavior?; and (2) to what extent do individual domestic violence suspects increase, decrease, or maintain the severity of their attacks on the same victim over time?

We will discuss the results for each of our two research questions separately for each of the sites. We begin with a description of the analytic methods we use in this study. Next, we turn to a discussion of the specialization question using official arrest data from the Charlotte, Colorado Springs, Milwaukee, and Omaha sites. We were unable to locate detailed information on prior arrest records of the domestic violence suspects in the Miami-Dade study so it is not included in this part of the study. Next, we present the results of our escalation study using victim interview data from the Charlotte, Miami-Dade, Milwaukee, and Omaha sites. As noted by Maxwell, Garner, and Fagan (2002:54, 60), the interviews in Colorado Springs were conducted in a different manner than the interviews in the other sites. To maintain a high level of comparability between the sites, we elected not to include the Colorado Springs interview data in our analysis. After describing each of the site-specific results, we summarize our findings by conducting a formal comparison of our parameter estimates between the sites. ${ }^{5}$

\section{Analytic Plan}

Our specialization analysis focus is on estimating the conditional probability that an individual entering the experiment with a prior record has experienced arrests 
This document is a research report submitted to the U.S. Department of Justice. This report has not

been published by the Department. Opinions or points of view expressed are those of the author(s)

and do not necessarily reflect the official position or policies of the U.S. Department of Justice.

exclusively for violent criminal behavior, $s_{\mathrm{v}}$. We refer to this conditional probability as a specialization parameter because it measures the proportion of individuals with prior records who are violent specialists. Because our task is an inferential one, we are concerned with obtaining a point estimate of the specialization parameter but we are also concerned with understanding the amount of uncertainty surrounding the parameter estimate. Criminologists conventionally use standard errors and significance tests for expressing uncertainty about parameter estimates but, as Maxwell and his colleagues (2002:64) observed, "the use of statistical significance tests is technically not appropriate for nonprobability samples such as those used in the Minneapolis and SARP experiments." Such tests and indices are even less useful when sample sizes are small (say below 20-30 cases) as they are in some of the analysis results described in this paper. Furthermore, some of our specialization, escalation, and de-escalation parameters are estimated close to the boundary of the parameter space (i.e., 0 or 1 ). Conventional confidence interval calculations fail in this setting but they are not problematic for Bayesian posterior probability interval estimation.

Our analytic method avoids the ambiguities of interpreting significance tests and standard errors that plague much of the domestic violence literature based on nonprobability samples. Instead, we rely on a Bayesian framework which provides us with parameter estimates and uncertainty measures that are easy to interpret. Furthermore, there are no difficulties created by small sample sizes; there will simply be greater uncertainty in the analysis results. The Bayesian framework used here is

\footnotetext{
${ }^{5}$ Since the original SARP experiments did not exclude on gender, we did not impose any such exclusion in our analysis.
} 
particularly appropriate for scientific problems where only one or two parameters need to be estimated. This is because the method is computationally intensive and is much more difficult to implement in cases where many parameters need to be estimated.

Our main task in the specialization analysis is to use the official records available in the SARP data to infer the probability distribution of the specialization parameter, $S_{\mathrm{V}}$, for each of the sites. In each site, we begin by identifying the arrest records of each of the suspects entering the experiment. We then divide each of the $N$ suspects into one of two groups: those with a prior arrest record, $N_{\mathrm{p}}$, and those without a prior arrest record, $N_{\mathrm{p}^{\prime}}$. The population of interest to us includes those with a prior arrest record which is comprised of $N_{\mathrm{p}}$ individuals. Within that population, we divide each of the $N_{\mathrm{p}}$ individuals into two groups: those who have exclusively violent arrests, $n_{\mathrm{v}}$, and those with other types of activity, $n_{\mathrm{v}^{\prime}}$, in their records. With these terms in hand, we turn next to the analytic framework for our specialization analysis.

We do not and cannot definitively know the tendency of offenders to specialize in violence, $s_{\mathrm{v}}$, but we can estimate the probability distribution of that tendency and take as our point estimate the value of $s_{\mathrm{v}}$ that maximizes the conditional probability of $s_{\mathrm{v}}$ given the observed official record data, $p\left(s_{\mathrm{v}} \mid N_{\mathrm{p}}, n_{\mathrm{v}}\right)$. Like all conditional probabilities, this conditional probability can be solved with Bayes' theorem:

$$
p\left(s_{v} \mid N_{p}, n_{v}\right)=\frac{p\left(N_{p}, n_{v} \mid s_{v}\right) \times p\left(s_{v}\right)}{\int p\left(N_{p}, n_{v} \mid s_{v}\right) \times p\left(s_{v}\right) d s_{v}}
$$

where $p\left(N_{p}, n_{v} \mid s_{v}\right)$ is the likelihood function for a binomial problem with $N_{\mathrm{p}}$ trials and $n_{v}$ events. Eq. (1) gives the posterior probability distribution of $s_{\mathrm{v}}$ after conditioning on the 
observed official record data. The binomial likelihood function for this problem is given by:

$$
p\left(N_{p}, n_{v} \mid s_{v}\right)=\left(\begin{array}{l}
N_{p} \\
n_{v}
\end{array}\right) \times s_{v}^{n_{v}} \times\left(1-s_{v}\right)^{N_{p}-n_{v}}
$$

which is straightforward to implement. It is less straightforward to obtain a distribution for $p\left(s_{v}\right)$ and to numerically evaluate the integral in the denominator of eq. (1). In the Bayesian framework, the distribution of $p\left(s_{v}\right)$ is called a prior distribution because it is not supplied by the data (Iversen, 1984:18-34). We solve the problem of specifying the distribution of $p\left(s_{v}\right)$ by assuming that $s_{\mathrm{v}}$ can only take on discrete values in the interval $[0.001,0.999]$. Next, we assume that $p\left(s_{v}\right)$ is uniform or equal at each value in the sample space:

$$
p\left(s_{v}=0.001\right)=p\left(s_{v}=0.002\right)=\ldots=p\left(s_{v}=0.999\right)=\frac{1}{999}
$$

which implies that we believe each possible value of $s_{\mathrm{v}}$ is equally probable before we examine the observed data.

This assumption leads to an important simplification of eq. (1) which we use in all of our analyses:

$$
p\left(s_{v}=j \mid N_{p}, n_{v}\right)=\frac{p\left(N_{p}, n_{v} \mid s_{v}=j\right) \times p\left(s_{v}=j\right)}{\sum_{j \in[0.001,0.999]} p\left(N_{p}, n_{v} \mid s_{v}=j\right) \times p\left(s_{v}=j\right)}, j=0.001,0.002, \ldots, 0.999
$$

and the value of $j$ that maximizes the posterior probability of $s_{\mathrm{v}}, p\left(s_{\mathrm{v}} \mid N_{\mathrm{p}}, n_{\mathrm{v}}\right)$, is called the maximum posterior probability estimate of $s_{\mathrm{v}}$. Entering each value of $j$ from the above sample space into eq. (2), and the binomial likelihood below: 


$$
p\left(N_{p}, n_{v} \mid s_{v}=j\right)=\left(\begin{array}{l}
N_{p} \\
n_{v}
\end{array}\right) \times j^{n_{v}} \times(1-j)^{N_{p}-n_{v}}
$$

we calculate the posterior probability of $s_{\mathrm{v}}$ so that the maximum posterior probability estimate of $s_{\mathrm{V}}$ is the estimated value of $s_{\mathrm{V}}$ that is most probable after conditioning on the data. This is an intuitively attractive rationale for choosing an estimate, but this method will produce the same point estimate as standard methods for calculating proportions and probabilities. We prefer this method because it provides us with an estimate of the full probability distribution for $S_{\mathrm{v}}$. With this distribution in hand, we can interpret a 95\% probability interval for the distribution of $s_{\mathrm{v}}$ to mean that there is a 95\% probability that $s_{\mathrm{v}}$ lies in an interval bounded by $\left[s_{\mathrm{vL}}, S_{\mathrm{vH}}\right]$. A 95\% confidence interval calculated under assumptions of simple random sampling cannot be interpreted in this fashion (Iversen, 1984:11). In addition, some of our parameter estimates will be very close to zero implying a lower 95\% confidence limit that is less than zero which is impossible for a probability parameter. The 95\% probability interval produced by the calculations presented above does not suffer from this defect. Most importantly, a clear interpretation of the $95 \%$ probability interval is necessary for our purposes because we will be comparing our specialization analysis results across the different study sites.

Our analysis of escalation and de-escalation of attack severity involves analytic issues that are similar to those encountered in the specialization analysis. But the escalation and de-escalation analyses presented in this paper rely on the victim interviews about violence after the presenting incident rather than the official records which focused 
on the arrest records of suspects prior to the presenting incident. ${ }^{6}$

Each of the sites made an effort to interview the presenting incident victims. The interviews asked victims who agreed to participate in the survey to describe the level of injury they experienced during the presenting incident. We divided the population of respondents, $N_{\mathrm{r}}$, into two groups: (1) those who experienced an injury as a result of the attack, $N_{\mathrm{i}}$; and (2) those who did not experience an injury, $N_{\mathrm{i}}$ '. The interviews also asked respondents whether there had been any new attacks between the presenting incident and the interview. Although we will define "injury" within the context of each study below, we note that for purposes of this study, we only count injuries as incidents resulting in cuts, bruises, scratches, unconsciousness, broken bones, broken teeth, eye and ear injuries, knife wounds, or gunshot wounds. This definition excludes slapping, pulling hair, punching, pushing or shoving, threats, and other attacking behaviors unless they produce one or more of the types of injuries listed above on the victim. This definition of injury, though arbitrary, sets a high but still quite frequently attained threshold for an incident to be classified as an injury-producing.

So, each of the two populations, $N_{\mathrm{i}}$ and $N_{\mathrm{i}}^{\prime}$ is comprised of two subpopulations:

(1) those who experienced a new attack, $N_{\mathrm{i} 1}$ and $N_{\mathrm{i} 1}$ '; and (2) those who did not experience a new attack, $N_{\mathrm{i} 0}$ and $N_{\mathrm{i} 0}{ }^{\prime}$. Our focus in the escalation and de-escalation analyses will be on the individuals comprising the population of victims who reported at least one new attack in their interviews, $N_{\mathrm{i} 1}$ and $N_{\mathrm{i} 1}$ '.

\footnotetext{
${ }^{6}$ There is no clear indication from the data or codebooks that the victim interviews were contingent on the original victim-offender relationship. Thus, in every case analyzed, there was no specific assumption or requirement that the victim was still in a relationship or residing with the offender after the initial, reported incident.
} 
Consider the population of victims who experienced no injury in the presenting incident attack but who went on to participate in the survey and report a new victimization. Designating this population by $N_{\mathrm{i} 1}$ ', we divide each individual in that population into two groups: (1) those who experienced an injury in at least one of their new victimizations, $n_{\mathrm{i} 1}$; and (2) those who did not experience an injury in any of their new victimizations, $n_{\mathrm{i} 1}^{\prime}$. Therefore, $N_{i 1}^{\prime}=n_{e}+n_{e}^{\prime}$ where $n_{\mathrm{e}}$ identifies the population of people who experience an escalation in the severity of attacks against them by the suspect. The escalation parameter, $e$, measures the conditional probability that an individual who was victimized without injury at the presenting incident and who went on to experience at least one new victimization during the interview follow-up period is victimized with injury in at least one of those new victimization incidents. It follows that $1-e$ is the probability that an individual who experiences subsequent victimizations and who was victimized without injury at the presenting incident receives an injury in at least one of the subsequent victimizations reported on the interview. The posterior probability distribution is given by:

$$
p\left(e=j \mid N_{i 1}{ }^{\prime}, n_{e}\right)=\frac{p\left(N_{i 1}{ }^{\prime}, n_{e} \mid e=j\right) \times p(e=j)}{\sum_{j \in[0.001,0.999]} p\left(N_{i 1}{ }^{\prime}, n_{e} \mid e=j\right) \times p(e=j)}, j=0.001,0.002, \ldots, 0.999
$$

where the likelihood function in eq. (3) is given by the binomial distribution and is parameterized as:

$$
p\left(N_{i 1}^{\prime}, n_{e} \mid e=j\right)=\left(\begin{array}{l}
N_{i 1}{ }^{\prime} \\
n_{e}
\end{array}\right) \times j^{n_{e}} \times(1-j)^{N_{i 1}{ }^{\prime}-n_{e}}
$$

for each of the values of $j$ above, and the prior distribution for $e$ is given by: 


$$
p(e=0.001)=p(e=0.002)=\ldots=p(e=0.999)=\frac{1}{999}
$$

to express our lack of prior information about the likely distribution of $e$.

Next, consider the population of victims who reported an injury in the presenting incident victimization and went on to report a new victimization after the presenting incident, $N_{\mathrm{i}}$. We divide each of the cases into one of two groups: (1) those who experienced an injury in at least one of their subsequent victimizations, $n_{d}$; and (2) those who experienced no injury in any of their subsequent victimizations, $n_{\mathrm{d}}$. In symmetry with the escalation analysis, $N_{\mathrm{i}}=n_{\mathrm{d}}+n_{\mathrm{d}}$ ' where $n_{\mathrm{d}}$ represents the population of individuals who were victimized after the presenting incident in which the severity of the attack de-escalated from an attack with injury at the presenting incident to no attacks with injury after the presenting incident. The posterior probability distribution for the deescalation parameter, $d$, is given by:

$$
p\left(d=j \mid N_{i 1}, n_{d}\right)=\frac{p\left(N_{i 1}, n_{d} \mid d=j\right) \times p(d=j)}{\sum_{j \in[0.001,0.999]} p\left(N_{i 1}, n_{d} \mid d=j\right) \times p(d=j)}, j=0.001,0.002, \ldots, 0.999
$$

and the likelihood function for all $j$ is given by:

$$
p\left(N_{i 1}, n_{d} \mid d=j\right)=\left(\begin{array}{l}
N_{i 1} \\
n_{d}
\end{array}\right) \times j^{n_{d}} \times(1-j)^{N_{i 1}-n_{d}}
$$

and the prior distribution for $d$ is given by:

$$
p(d=0.001)=p(d=0.002)=\ldots=p(d=0.999)=\frac{1}{999}
$$

thus ensuring that all possible values of $d$ (to three decimal places) have an equal probability before examining the data. Also in symmetry with the escalation analysis, the de-escalation parameter, $d$, measures the probability that an individual who reported 
This document is a research report submitted to the U.S. Department of Justice. This report has not

been published by the Department. Opinions or points of view expressed are those of the author(s)

and do not necessarily reflect the official position or policies of the U.S. Department of Justice.

injury at the presenting incident and at least one subsequent victimization also reports no injury at the subsequent victimization. In addition, $1-d$ represents the probability that an individual who reported injury at the presenting incident and a new victimization reported at least one injury inflicted by her abuser during the interview follow-up period.

\section{Specialization Analysis Results}

In this section, we describe our substantive findings about the prevalence of specialized violent offending among suspects entering the SARP projects in Charlotte, Colorado Springs, Milwaukee, and Omaha. For each site, we will describe the data used for the analysis and we will present our parameter estimates. Then, we summarize our findings.

\section{Charlotte Analysis}

The Charlotte SARP data used for this analysis are based on data from 650 unique suspects that entered the experiment between August 1987 and June 1989. There were 36 cases where the same suspect entered the experiment twice (for a total of 686 cases); we focus exclusively on the 650 unique suspects. A frequency count of arrests for the following categories of offenses prior to the presenting incident were included in the data: (1) the number of arrests for an assault; (2) the number of arrests for other violent crimes; (3) the number of arrests for property crimes; and (4) the number of arrests for other types of crime. Categories (1) and (2) were summed to create a measure of the number of arrests for violent crimes and categories (3) and (4) were summed to create a 
measure of the number of arrests for non-violent crimes. ${ }^{7}$

Next, each individual's offense history was examined to determine whether there were any prior arrests. This effort revealed that $N_{\mathrm{p}}=111(17.1 \%)$ of the $N=650$ suspects had at least one prior arrest. The majority (86) of these 111 individuals had been arrested exclusively for property or other offenses while only 25 had been arrested for a violent offense. Out of these 25 cases, 11 suspects had been arrested for both violent and non-violent offenses in the past. The remaining 14 cases represent the population of violent specialists as they had been arrested exclusively for violent offenses in the past. Thus, our estimate of the prevalence of specialized violent offending in the Charlotte data is given by $s_{v}=\frac{14}{111}=12.6 \%$ (see Figure 1 ). The overwhelming majority of offenders with a prior arrest record in the Charlotte data have been involved in non-violent offending activity in addition to the violence that brought them into the SARP experiment. The 95\% probability interval surrounding this point estimate is bounded on the low end by 0.077 (the $2.5 \%$ ile of the distribution) and on the high end by 0.200 (the 97.5\%ile of the distribution).

\section{Colorado Springs Analysis}

The arrest data from the Colorado Springs study were obtained from a file that documents the pre-experiment arrest history for each of the suspects. Cases were enrolled between March 1987 and April 1989. There were a total of 1,548 cases in the file but 22 of these cases had duplicate suspect identification numbers. After deleting the

\footnotetext{
${ }^{7}$ Two qualifications regarding the Charlotte data are in order. First, the Charlotte specialization analysis are based on data from state records only. Second, the state records only cover the five years prior to the reporting incident.
} 
This document is a research report submitted to the U.S. Department of Justice. This report has not

been published by the Department. Opinions or points of view expressed are those of the author(s)

and do not necessarily reflect the official position or policies of the U.S. Department of Justice.

22 duplicates, one additional case that was missing some of the arrest information was deleted. This produced an analysis file with 1,525 unique suspects. The file contained frequency information on the number of counts charged for each of a wide variety of offense categories including felony assault, felony sexual assault, robbery, burglary, arson narcotics, third-degree assault, alcohol, menacing, harassment, false imprisonment, misdemeanor sexual assault, fighting, and other. Domestic counts of these same offenses were also collected. For purposes of this analysis, we treated felony assault, felony sexual assault, robbery, third-degree assault, false imprisonment, misdemeanor sexual assault, and fighting as violent offenses. We defined all other categories as non-violent offenses. $^{8}$

Analysis of the prior record data identified $N_{\mathrm{p}}=624$ individuals $(40.9 \%$ of 1,525$)$ with at least one prior arrest. Among these 624 individuals, only $n_{\mathrm{v}}=41\left(\frac{41}{624}=6.6 \%\right)$ could be characterized as violent specialists (i.e., all prior arrests for violent offenses). The modal category was non-violent offenses (332 suspects) followed by the generalist category comprised of 251 suspects who had been charged with violent and non-violent offenses in the past. Figure 2 presents the posterior distribution of the violent specialization parameter. The density peaks at $6.6 \%$ but an interesting feature of this distribution is the extent to which it is compressed around the maximum posterior point estimate; the lower bound of the $95 \%$ probability interval is 0.048 and the upper bound is 0.087. The Colorado Springs interval is considerably narrower than the Charlotte interval

\footnotetext{
${ }^{8}$ As in any analysis that places distinct offenses into more general categories, some readers may offer different categorization schemes (i.e., placing robbery in the non-violent category). We attempted to
} 
This document is a research report submitted to the U.S. Department of Justice. This report has not

been published by the Department. Opinions or points of view expressed are those of the author(s)

and do not necessarily reflect the official position or policies of the U.S. Department of Justice.

but, importantly, the intervals for the two sites do overlap to some extent.

\section{Milwaukee Analysis}

The Milwaukee study enrolled 1,200 eligible domestic assault cases between

1987 and 1989. Some of the cases involved suspects who made repeat appearances in the study. After deleting the duplicate records of multiple appearance suspects and one case with some missing offense information, we were left with an analysis file comprised of 1,124 unique suspects. Information about the prior arrest records for each of the suspects was summarized in frequency count form. Thus, for each individual, information about the total number of prior arrests for theft, domestic violence, drug offenses, all other violent offenses, and all other offenses were available. We classified domestic violence and all other violent offenses as violence and we treated all the other categories as nonviolent offenses.

Analysis of the data revealed that 467 suspects had no prior record while the remaining $N_{\mathrm{p}}=657$ (58.5\%) had at least one prior arrest. Nearly half of these suspects (307; 46.7\%) had records exhibiting involvement in both violent and non-violent offending activity while another 196 suspects (29.8\%) had records comprised entirely of non-violent offenses. The final 154 cases $\left(s_{\mathrm{v}}=23.4 \%\right)$ represent the population of violent specialists $\left(n_{\mathrm{v}}\right)$ in the Milwaukee data. Figure 3 presents the posterior distribution of the violent specialization parameter which indicates a tight 95\% probability interval bounding the maximum posterior estimate. The lower bound of the interval (2.5\%ile) is 0.203 and the upper bound (97.5\%ile) is 0.268 . This distribution is substantially higher

closely follow much of the previous criminal careers research in our categorization scheme, but recognize that other decisions are equally appropriate. 
This document is a research report submitted to the U.S. Department of Justice. This report has not

been published by the Department. Opinions or points of view expressed are those of the author(s)

and do not necessarily reflect the official position or policies of the U.S. Department of Justice.

than what we observed in Colorado Springs. In addition, the lower bound of the

Milwaukee interval slightly exceeds the upper bound of the Charlotte interval.

\section{Omaha Analysis}

A total of 621 cases entered the Omaha experiment between March 1986 and September 1987 but 44 of these cases were generated by repeat instances of criminal domestic violence. The twelve-month criminal history file from the project contains data on 577 unique suspects and the exact dates of each arrest. The criminal history file was merged with a police report file so the date of each arrest could be compared with the presenting incident date. Some of the arrests reported in this file occurred after the presenting incident. It turns out that our analysis results change somewhat depending on whether we include the arrests occurring after the presenting incident.

Considering only those arrests occurring before the presenting incident, $N_{\mathrm{p}}=363$ individuals had at least one arrest while the remaining $N_{\mathrm{p}}{ }^{\prime}=214$ individuals did not. Among the 363 suspects with a prior arrest record, 217 individuals had been arrested only for non-violent offenses while 130 individuals had been arrested for both violent and non-violent offenses. The remaining $n_{\mathrm{v}}=16$ individuals had been arrested exclusively for violent offenses in the past. This implies that the maximum posterior estimate of $s_{v}=\frac{16}{363}=4.4 \%$. Figure 4 presents the full posterior distribution of $s_{\mathrm{v}}$ using only those arrests occurring before the presenting incident date. This is the lowest estimate we have seen in any of the SARP data sets but it is close to the estimates produced in the Colorado Springs analysis and the 95\% probability intervals for the two sites exhibit considerable overlap. 
It is straightforward to estimate $s_{\mathrm{v}}$ including the full arrest history up to and including the year after the presenting incident so we conducted a second analysis to study this distribution. After including these additional arrests, we found that $N_{\mathrm{p}}=463$ individuals had experienced at least one arrest while $N_{\mathrm{p}}{ }^{\prime}=114$ individuals had not. Within the population of arrested individuals, 147 (31.7\%) had been arrested exclusively for non-violent offenses while 252 (54.4\%) individuals had been arrested for both violent and non-violent offenses. The remaining $n_{\mathrm{v}}=64$ individuals had been arrested exclusively for violent offenses producing a maximum posterior estimate of $s_{v}=\frac{64}{463}=13.8 \%$. The full posterior distribution of $s_{\mathrm{v}}$ is presented in Figure 5. The 95\% probability interval has a lower bound of $s_{\mathrm{vL}}=0.109$ and a upper bound of $s_{\mathrm{vH}}=0.172$. Although there is an increased level of violent specialization in this second analysis, it is also true that the overwhelming majority of suspects do not exhibit specialized violent offending in their arrest records in either of the two Omaha analyses.

\section{Summary of Specialization Analysis Results}

On balance, our review of SARP suspect arrest records indicates that most offenders do not engage in specialized violent offending. Of those who have been arrested, the vast majority have been arrested for non-violent offending over and above any arrests for violence they may have experienced. Table 1 summarizes the details of each of the analyses while Figure 6 shows the site-to-site variation in the posterior distribution of the specialization parameter. Despite this site-to-site variation, a basic story of low violence specialization consistently emerges. The highest levels of violence specialization were found in Milwaukee $\left(s_{\mathrm{v}}=0.236\right)$ while the lowest levels were found 
This document is a research report submitted to the U.S. Department of Justice. This report has not

been published by the Department. Opinions or points of view expressed are those of the author(s)

and do not necessarily reflect the official position or policies of the U.S. Department of Justice.

in Omaha (pre-presenting incident analysis, $\left.s_{\mathrm{v}}=0.044\right)$ and Colorado Springs $\left(s_{\mathrm{v}}=\right.$ 0.066). The Charlotte estimate occupied an intermediate position but because of the relatively small number of cases available for study in this site, the posterior probability distribution is flatter than the other sites reflecting greater uncertainty about the parameter estimate.

\section{Escalation and De-Escalation Analysis Results}

We now turn to our analysis of the SARP victim interview data to study escalation and de-escalation in the severity of attacks against the same victim after the presenting incident. In each of the sites, efforts were made to interview victims about the level of injury they experienced during the presenting incident. Victims were also interviewed about the level of injury experienced in new assaults occurring between the presenting incident and the time of the interviews. Attempts were made to contact victims for an initial interview and a follow-up interview (except in Omaha where there were two follow-up interviews - six months and twelve months after the presenting incident). As mentioned earlier, the interviews in Colorado Springs were conducted differently than those in the other sites and those data are not analyzed here. Thus, interview data from each of the other sites was examined (Charlotte, Miami-Dade, Milwaukee, and Omaha). A summary of our escalation and de-escalation findings is presented at the end.

\section{Charlotte Analysis}

In Charlotte, initial interviews were targeted for a one-month follow-up period and were obtained from 419 victims (61\% of the 686 eligible cases) while six-month 
This document is a research report submitted to the U.S. Department of Justice. This report has not

been published by the Department. Opinions or points of view expressed are those of the author(s)

and do not necessarily reflect the official position or policies of the U.S. Department of Justice.

interviews were obtained for 324 victims (47\% of the 686 eligible cases). A total of 415 victims provided injury information on the initial interview, while 320 victims provided injury information on the six-month interview. Our initial focus is on questions that were asked about the presenting incident. Each victim was asked whether: (1) you were hit on the head and blacked out or knocked out; (2) you had any broken bones or teeth; (3) you had any scratches or bruises; (4) you were shot with a gun; and (5) you were cut with a knife. Victims who answered any of these questions with a "yes" were coded as having experienced an injury at the presenting incident. The analysis shows that $N_{\mathrm{i}}=219$ $\left(\frac{219}{415}=52.7 \%\right)$ victims reported being injured in at least one of these ways at the presenting incident while the remaining $N_{\mathrm{i}}^{\prime}=196$ victims reported none of these injuries at the presenting incident.

The initial interview also asks about new attacks during the period between the presenting incident and the initial interview. Victims who reported experiencing new attacks were asked about the first incident of violence, the most recent incident, and the most serious interim incident if there was at least one occurrence of interim violence between the first and most recent incidents. The injury questions asked about the presenting incident were also asked about repeat incidents. Among the $N_{\mathrm{i}}^{\prime}=196$ victims who experienced no injury at the presenting incident, $N_{\mathrm{i} 1}{ }^{\prime}=26\left(\frac{26}{196}=13.3 \%\right)$ went on to experience a new attack before the initial interview while the other $N_{\mathrm{i} 0}{ }^{\prime}=170$ did not. For this group of 26 victims, we estimate the probability of experiencing at least one of the above-listed injuries. The maximum posterior estimate of this probability is given by 
$e=\frac{n_{e}}{N_{i 1}{ }^{\prime}}=\frac{18}{26}=0.692$ which indicates that the majority of those who escaped the

presenting incident without injury but went on to experience a new attack before the initial interview reported being injured on the interview.

The six-month interview asks victims about new victimizations since the initial interview. It asks about the first and most recent victimization as well as about interim victimization between the first and most recent victimizations. The injury questions on the six-month interview are the same as those used in the initial interview. Our analysis of the six-month interview data includes only those individuals participating in the sixmonth interview but injury questions from both the initial and the six-month interview were used to classify individuals as having been injured in a new attack by the time of the six-month interview. So, an individual who is characterized as being a victim of injury escalation at the initial interview was characterized as a victim of injury escalation through the six-month interview even if no additional injuries were reported on the sixmonth interview. Individuals who did not complete the six-month interview were not included in the analysis regardless of their injury status at the initial interview.

Out of the 320 individuals who provided information about injury through the sixmonth interview, $N_{\mathrm{i}}=172\left(\frac{172}{320}=53.8 \%\right)$ reported experiencing an injury at the presenting incident. The remaining $N_{\mathrm{i}}^{\prime}=148$ reported no injury at the presenting incident. Among those victims who were not injured at the presenting incident, $N_{\mathrm{i} 1}{ }^{\prime}=43$ $\left(\frac{43}{148}=29.1 \%\right)$ reported experiencing a new attack between the presenting incident and the six-month interview. Within this group of repeat victims who experienced no injury 
at the presenting incident, we estimate the probability of injury, which, for this group, is the probability of escalation by $e=\frac{n_{e}}{N_{i 1}{ }^{\prime}}=\frac{36}{43}=0.837$. In both the initial and the sixmonth interviews in Charlotte, then, there is evidence of significant escalation between the presenting incidents and the time of the interviews. Figure 7 presents the full posterior probability distribution for both of the Charlotte escalation parameters based on the initial and six-month interview analyses.

We now turn to an analysis of de-escalation within the group of $N_{\mathrm{i}}=219$ victims who reported experiencing an injury in their presenting incident victimization on the initial interview. The initial interview data reveal that $N_{\mathrm{i} 1}=52\left(\frac{52}{219}=23.7 \%\right)$ of these individuals experienced a new attack by the time of the initial interview. Within this group of repeat victims, $45\left(\frac{45}{52}=86.5 \%\right)$ went on to be injured again while $n_{d}=7$ were not injured again and are, therefore, classified as experiencing de-escalation. Thus, the maximum posterior estimate for the de-escalation parameter within this population is given by $d=\frac{n_{d}}{N_{i 1}}=\frac{7}{52}=0.135$.

At the six-month interview, our base population for studying de-escalation is the $N_{\mathrm{i}}=172$ individuals who experienced an injury at the presenting incident and participated in the six-month interview. Within this group of victims, $N_{\mathrm{i} 1}=77$ individuals report at least one new victimization between the presenting incident and the six-month interview. In this population, we estimate the proportion of individuals who are not injured; this will be our estimated probability of de-escalation. The data indicate that $n_{\mathrm{d}}=6$ out of the 77 
victims in this group were not injured. This implies that the maximum posterior

estimated de-escalation probability is $d=\frac{n_{d}}{N_{i 1}}=\frac{6}{77}=0.078$. The full posterior

probability distributions for the initial and six-month interview-based de-escalation

parameters are presented in Figure 8. In both sets of analyses the prevalence of de-

escalation is quite close to zero. Taken together with the escalation findings, the weight

of the evidence suggests that new attacks have a relatively high likelihood of being

accompanied by new injury to the victim.

\section{Miami-Dade Analysis}

The Miami-Dade study enrolled 907 eligible cases between August 1987 and January 1989. Documentation associated with the data files indicates that initial interviews were completed with 595 victims and six-month interviews were completed with 395 victims. When we merged the initial interview and six-month interview files, 607 unique cases were identified. Twelve of these 607 cases had information from the six-month interview but no information from an initial interview. We deleted these observations plus one additional observation that had missing data on the gateway victimization question on the initial interview. This left us with an initial interview database comprised of 594 victims. After deleting individuals who appeared in the initial interview database but not in the six-month interview database plus one additional person with missing information on the six-month victimization gateway question we were left with a six-month database comprised of 371 victims.

At the initial interview, victims were asked a number of questions about the presenting incident including the level of injury experienced as a result of that incident. 
This document is a research report submitted to the U.S. Department of Justice. This report has not

been published by the Department. Opinions or points of view expressed are those of the author(s)

and do not necessarily reflect the official position or policies of the U.S. Department of Justice.

Injury items included the following: (1) loss of consciousness (blackout); (2) internal injuries; (3) gunshot wound; (4) knife wound; (5) eye or teeth injury; (6) broken bones/dislocated joints; (7) concussion/bump on head; (8) serious cuts, bruises or burns; and (9) minor cuts, scratches/bruises. Out of the 594 victims interviewed, 403 (67.8\%) reported having received at least one of these injuries while the remaining 191 (32.2\%) victims reported receiving none of these injuries.

The initial interview also asked victims about attacks between the presenting incident and the interview. Detailed information about the first two attacks was solicited including information about injuries experienced by the victim. The items used on the injury scale above were also used to characterize injuries for subsequent attacks.

We first consider the results of our escalation analysis. Out of the 191 victims reporting no injury at the presenting incident, $N_{\mathrm{i} 1}{ }^{\prime}=12$ reported at least one new attack before the initial interview; thus, the prevalence of revictimization within this population was $6.3 \%$. Our focus in this analysis is on how many of the 12 victims reported an injury on the initial interview; such cases are construed as escalations because they move from a no-injury status at the presenting incident to an injury status on the initial interview. The analysis reveals that $n_{\mathrm{e}}=2$ of these twelve individuals reported an injury yielding a maximum posterior estimate of $e=\frac{2}{12}=0.167$.

Moving to the six-month follow-up, victims were asked detailed questions about the first incident of violence that occurred between the initial and the six-month interviews. The injury scale used above was also used on the six-month interview. Within the population of 371 respondents, 117 victims reported no injury at the 
This document is a research report submitted to the U.S. Department of Justice. This report has not

been published by the Department. Opinions or points of view expressed are those of the author(s)

and do not necessarily reflect the official position or policies of the U.S. Department of Justice.

presenting incident. Within this group, 23 victims (19.7\%) reported at least one new attack by the six-month interview. Out of these 23 victims, $n_{\mathrm{e}}=7$ reported experiencing an injury implying a maximum posterior escalation estimate of $e=\frac{7}{23}=0.304$. The full posterior distributions for both of the Miami-Dade escalation parameters are presented in Figure 9. The small number of cases involved in this analysis means that these distributions are highly dispersed. In fact, the posterior probability of the point estimates are lower for these escalation parameters than for any of the other parameters estimated in this paper.

We now address the issue of de-escalation in the Miami-Dade data. At the initial interview, $N_{\mathrm{i}}=403$ out of the 594 victims (67.8\%) reported experiencing at least one of the above-named injuries at the presenting incident. Our analysis identifies this population as the set of individuals who could potentially experience de-escalation. Within this population of 403 victims, $N_{\mathrm{i} 1}=72$ (17.9\%) reported at least one new attack by the initial interview. Our analysis reveals that $n_{\mathrm{d}}=30$ of these victims did not experience an injury while the remaining $n_{\mathrm{d}}{ }^{\prime}=42$ did. Thus, the maximum posterior estimate of the initial interview-based de-escalation parameter is $d=\frac{30}{72}=0.417$.

Analysis of the six-month interview data, revealed that $N_{\mathrm{i}}=254$ of the 371 victims (68.5\%) reported an injury as a result of the presenting incident. Combining information from the initial and six-month interviews, $N_{\mathrm{i} 1}=75$ of these victims reported a new attack between the presenting incident and the follow-up interview. Among these 75 victims, $n_{\mathrm{d}}=33$ reported no injury as a result of new attacks while the other $n_{\mathrm{d}}{ }^{\prime}=42$ 
This document is a research report submitted to the U.S. Department of Justice. This report has not

been published by the Department. Opinions or points of view expressed are those of the author(s)

and do not necessarily reflect the official position or policies of the U.S. Department of Justice.

reported at least one new injury. This implies an estimated de-escalation probability of

$d=\frac{33}{75}=0.440$. The full posterior distributions for both the initial-interview and sixmonth interview-based measures of de-escalation are presented in Figure 10. These estimated distributions overlap closely and indicate that individuals who were injured at the presenting incident and who experienced one or more new attacks had a 40-45\% chance of reporting no injury (de-escalating) on the survey.

\section{Milwaukee Analysis}

The Milwaukee project did not attempt to conduct an initial interview with all victims. As Maxwell, Garner, and Fagan (2002:54) point out, "25\% of victims were not interviewed until six months after the presenting incident." The database documentation states that "a total of 705 initial interviews were conducted from the 1,200 eligible domestic battery incidents." Our inquiry into the initial interview database revealed five individuals with missing information on the injury questions associated with the presenting incident. Our initial interview analysis database is comprised of the remaining 700 victims and our six-month interview database will be comprised of the subset of 599 of these 700 victims who go on to participate in the six-month interview. The initial interview queried victims about new attacks after the police response (different sets of questions for informal treatment and arrested cases), and then about the first and most recent attacks (not including a reunion incident if one occurred). At the six-month interview, victims were asked about the first and most recent attacks following the presenting incident. At the presenting incident and the follow-up incidents, victims were asked about the following injuries: (1) internal injuries; (2) scratches, cuts, bruises; (3) 
concussion; (4) broken bones/teeth; (5) knife wound; and (6) gunshot wound.

At this initial interview, $N_{\mathrm{i}}^{\prime}=170$ (24.3\%) victims reported receiving no injury at the presenting incident while the remaining $N_{\mathrm{i}}=530$ (75.7\%) victims reported receiving at least one of the above injuries at the presenting incident. The $N_{\mathrm{i}}{ }^{\prime}=170$ victims reporting no injury at the presenting incident constitute our population at risk of injury escalation. A total of $N_{\mathrm{i} 1}{ }^{\prime}=47$ individuals reported experiencing a new victimization by the time of the initial interview. But only three of these new attacks was accompanied by an injury yielding a maximum posterior escalation estimate of $e=\frac{3}{47}=0.064$.

At the six-month interview, the $N=599$ participants can be divided into two groups: (1) the $N_{\mathrm{i}}=457$ victims who reported an injury due to the presenting incident; and (2) the $N_{\mathrm{i}}^{\prime}=142$ victims who reported no injury due to the presenting incident. The group of $N_{\mathrm{i}}{ }^{\prime}=142$ is the population at risk of escalation. The analysis identified $N_{\mathrm{i} 1}{ }^{\prime}=62$ individuals who reported a new victimization between the presenting incident and the sixmonth interview. An examination of the injury data indicated that the proportion of these $N_{\mathrm{i} 1}^{\prime}=62$ victims who reported an injury was $e=\frac{22}{62}=0.355$. Figure 11 presents the full posterior probability distribution for both the initial- and six-month interview-based estimates of the escalation parameter.

As noted above, $N_{\mathrm{i}}=530(75.7 \%$ of $N=700)$ victims reporting an injury at the presenting incident were identified. Among these $N_{\mathrm{i}}=530$ victims, $N_{\mathrm{i} 1}=126(23.8 \%)$ reported a new attack between the presenting incident and the initial interview. Our maximum posterior estimate of the de-escalation parameter for this population is the 
proportion of these 126 victims who report receiving no injury in a follow-up attack; in this instance, that estimate is given by: $d=\frac{91}{126}=0.722$. When we consider the sixmonth interview, however, this estimate drops considerably.

The six-month interview followed up $N=599$ victims of whom $N_{\mathrm{i}}=457$ (76.3\%) reported an injury from the above list at the presenting incident. Nearly half of these victims ( $N_{\mathrm{i} 1}=212 ; 46.4 \%$ ) reported being revictimized between the presenting incident and the six-month interview. Within this group of repeat victims, $n_{\mathrm{d}}=81$ reported experiencing no injury as a result of their repeat victimization; our maximum posterior estimate of de-escalation is given by $d=\frac{81}{212}=0.382$. Contrary to the initial interview inference, this result implies that the majority of the repeat victims were, in fact, experiencing new injuries. The full posterior distribution for both the initial- and sixmonth interview-based estimates of the Milwaukee de-escalation parameter are presented in Figure 12 and highlight the different inferences produced by the two sets of interview results.

\section{Omaha Analysis}

The Omaha protocol included three interviews for each victim agreeing to participate. The initial interview $(\mathrm{N}=477)$, targeted for one week after the presenting incident asked detailed questions about that incident including whether they experienced each of the following injuries: (1) bruised/scratched; (2) cut/bleeding; (3) unconscious; (4) broken bones; and (5) head injuries.

Interviews conducted approximately six months $(\mathrm{N}=438)$ and one year $(\mathrm{N}=416)$ 
after the presenting incident asked questions about attacks occurring after the presenting incident. The six-month interview asked detailed questions about each of the first three incidents after the presenting incident while the one-year interview asked detailed questions about each of the first three incidents occurring after the six-month interview. The follow-up interviews asked slightly different questions about injuries than the initial one-week interview: (1) bruised/scratched; (2) cut; (3) knocked/choked unconscious; and (4) teeth/eyes/ears injured.

Using information provided by the $N=438$ six-month interview respondents, we found that $N_{\mathrm{i}}=335$ (76.5\%) reported they had been injured at the presenting incident while $N_{\mathrm{i}}^{\prime}=103$ said they had not been injured at the presenting incident. Almost half of the $N_{\mathrm{i}}^{\prime}=103$ noninjured victims went on to experience a new attack before the six-month interview $\left(N_{\mathrm{i} 1}{ }^{\prime}=51\right)$. Analysis of the injury data at the six-month interview revealed that $n_{\mathrm{e}}=20$ of these 51 victims experienced one or more of the above-listed injuries yielding a maximum posterior escalation parameter estimate of $e=\frac{20}{51}=0.392$.

At the one-year interview, $N_{\mathrm{i}}{ }^{\prime}=99$ non-injured presenting incident victims remained and $N_{\mathrm{i} 1}{ }^{\prime}=60(60.6 \%)$ of these victims had gone on to experience a new victimization between the presenting incident and the one-year interview. Out of these 60 victims, $n_{\mathrm{e}}=26$ went on to experience an injury; this implies that the probability of escalation within this group is $e=\frac{26}{60}=0.433$. These estimates imply that nearly half of the Omaha victims who were not injured at the presenting incident went on to experience an injury if they encountered additional assaults. The full posterior distributions for the 
This document is a research report submitted to the U.S. Department of Justice. This report has not

been published by the Department. Opinions or points of view expressed are those of the author(s)

and do not necessarily reflect the official position or policies of the U.S. Department of Justice.

six-month and one-year escalation parameters are presented in Figure 13.

As noted above, the majority of the Omaha respondents reported an injury at the presenting incident $\left(N_{\mathrm{i}}=335\right.$ at the six-month interview and $N_{\mathrm{i}}=317$ at the one-year interview). Our analysis of the six-month and one-year follow-up information revealed that the majority of the respondents experienced at least one new attack ( $N_{\mathrm{i} 1}=202$ at the six-month interview and $N_{\mathrm{i} 1}=221$ at the one-year interview). In both interviews, about half of the respondents experiencing a new attack reported an injury while about half did not $\left(d=\frac{115}{202}=0.569\right.$ at the six-month interview and $d=\frac{111}{221}=0.502$ at the one-year interview). This result implies that de-escalation and stable injury victimization were approximately equally prevalent outcomes for those who experienced new victimizations. The full posterior distributions for the de-escalation parameters in the Omaha study are presented in Figure 14.

\section{Summary of Escalation and De-Escalation Analysis Results}

Our escalation and de-escalation findings varied considerably from site-to-site. And, in some instances, our findings varied depending on the follow-up period within sites. Table 2 presents a summary of the escalation results and shows that, overall, the Charlotte analysis provides the highest escalation parameter estimates. In no other site, did the maximum posterior estimates of the escalation parameter exceed $50 \%$ (although some of the upper limits of the 95\% probability interval did exceed 50\%). The escalation parameter point estimates in the other sites - particularly at longer follow-up periods seem to have settled in a range between 0.3 and 0.5 indicating that about one-third to onehalf of victims who (1) had not been injured at the presenting incident and (2) went on to 
This document is a research report submitted to the U.S. Department of Justice. This report has not

been published by the Department. Opinions or points of view expressed are those of the author(s)

and do not necessarily reflect the official position or policies of the U.S. Department of Justice.

experience a new attack were actually injured as a result of that attack.

As Table 3 indicates, the Charlotte analysis also produced outlying de-escalation parameter estimates. By the six-month follow-up interview in Charlotte only about 8\% of those victims who experienced a new victimization and had been injured in the presenting incident escaped a subsequent injury. These estimates were substantially higher in the other sites $($ Miami-Dade $=44 \%$; Milwaukee $=38 \%$; and Omaha $=57 \%$ at six months and 50\% at one year) indicating that in most sites the follow-up victimizations represented a mixed bag of injury seriousness in comparison to the injuries encountered in the presenting incident.

\section{Discussion}

We began this analysis by asking two very basic criminal career questions that have escaped the research literature in domestic violence: (1) to what extent do domestic violence offenders exhibit a specialized tendency to engage exclusively in violent criminal behavior?; and (2) how prevalent are escalation and de-escalation in the seriousness of attacks by an offender against the same victim in a longitudinal sequence of criminal domestic violence? These are precisely the types of inquiries that National Research Council panels on Criminal Careers and Understanding and Preventing Violence have advocated (Blumstein et al., 1986; Reiss and Roth, 1993). The emphasis of our analysis has been to use the detailed official record and victim interview information collected by the SARP investigators to gain some insights into both parameters of domestic violence offenders' criminal careers. This is an important feature of our work because most criminal career/domestic violence studies do not integrate data 
This document is a research report submitted to the U.S. Department of Justice. This report has not

been published by the Department. Opinions or points of view expressed are those of the author(s)

and do not necessarily reflect the official position or policies of the U.S. Department of Justice.

from these two sources (i.e., official and self-report records). Our analysis of specialization and escalation in the SARP data has produced some interesting insights about both dimensions of the criminal careers of domestic violence offenders.

On the question of offending specialization, our analysis of official record data in Charlotte, Colorado Springs, Milwaukee, and Omaha indicates that few SARP domestic violence offenders have been specializing exclusively in violent criminal behavior. We were certainly able to identify many SARP offenders with violence in their official criminal histories, but the overwhelming majority of these individuals also had nonviolent offenses in their criminal histories. Consistent with many criminological theories and more general criminal careers research, our analysis suggests that criminal domestic violence is part of a larger cluster of serious problem behaviors in the lives of the people who commit it (e.g., Gottfredson and Hirschi, 1990). The domestic violence offender who is arrested only for violent criminal activity appears to be the exception rather than norm.

On the question of escalation and de-escalation in the seriousness of domestic violence, our analysis of victim interview data in the SARP sites of Miami-Dade, Milwaukee, and Omaha indicate that there is a heterogeneous mix of offenders who escalate and de-escalate the severity of their attacks over the relatively short-term followup periods covered by these studies. The exception site for both escalation and deescalation was Charlotte where tendencies of offenders to escalate the severity of attacks in low-injury presenting cases were pronounced and tendencies of offenders to deescalate the severity of attacks in high-injury presenting cases were virtually nonexistent. There are some important limitations to our study. The first is an exclusive focus 
This document is a research report submitted to the U.S. Department of Justice. This report has not

been published by the Department. Opinions or points of view expressed are those of the author(s)

and do not necessarily reflect the official position or policies of the U.S. Department of Justice.

on official records to study the question of specialization. More effort needs to be devoted to research on specialization through the use of offender and victim interviews to gain a broader understanding of the role different types of criminal activity plays in the lives of domestic violence offenders (Blumstein et al., 1986; Lynam et al., 2004).

Second, the interview information we have is plagued by our inability to know how the results would have changed if rates of missing data had been lower (see e.g., Sherman, 1992; Brame, 2000). Interview-based studies of criminal domestic violence victims are always subject to more than the usual degree of caution exercised in most survey studies because the response rates are lower and item measurement properties are not well understood. It is certainly plausible to claim that non-interviewed victims have a different victimization experience than interviewed victims (Saphire, 1994; Stasny, 1990:323-325; Stasny, 1991:302; Conaway, 1993:113; Kadane, 1985; Brame, 2000). As one reviewer commented, previous studies have shown that victims, when repeatedly surveyed, tend to underreport victimizations over time; this trend has implications for studying escalation of attacks when the only data used are victim reports. Unfortunately, official records will also suffer from the bias that they contain only a small snapshot of true, reported crime.

A third limitation has to do with our focus on comparatively less serious forms of domestic violence. This is based on the case selection criteria for the SARP studies which focused primarily on cases where the police maintain wide discretion about how to respond to the case (Maxwell et al., 2002). In general, for more injurious criminal domestic violence cases, the police are required by law to arrest and such cases were 
This document is a research report submitted to the U.S. Department of Justice. This report has not

been published by the Department. Opinions or points of view expressed are those of the author(s)

and do not necessarily reflect the official position or policies of the U.S. Department of Justice.

systematically excluded from the SARP studies. The criminal careers of felony domestic violence offenders might look quite different from those we have examined in this study.

Fourth, this study lacked many data points for studying escalation/de-escalation, and it is unlikely the case that two points in time can be definitively considered a trend. To draw the conclusion that an offender has become less violent over time should depend on more data points. Unfortunately, such data in the domestic violence area are rare, and as such, we encourage further resources on this front.

Finally, the SARP studies were designed to measure the short-term impact of arrest on the behavior of domestic violence offenders. But, it will be important going forward to trace the mix and progression of domestic violence offenders' criminal careers over longer follow-up periods. There is very little research examining the long-term careers of domestic violence offenders (see e.g., Sherman, 1992:212-246) but such research is badly needed.

With these limitations in hand, we envision a healthy research agenda that moves our preliminary work forward. First, while our effort was designed to document patterns of specialization and escalation, we were unable to distinguish the correlates associated with different escalation trajectories. Researchers should attempt to document the factors that distinguish between escalators, de-escalators, and/or those who maintain high or low levels of domestic violence. Specific study of the factors that are associated with escalation to injury or even fatal violence have important public health implications.

Second, while quantitative research can certainly document patterns of escalation and deescalation, qualitative studies are better suited to fill many of the holes in this line of 
This document is a research report submitted to the U.S. Department of Justice. This report has not

been published by the Department. Opinions or points of view expressed are those of the author(s)

and do not necessarily reflect the official position or policies of the U.S. Department of Justice.

research. For example, case study and/or life history efforts can provide rich information about how escalation works and the extent to which men deny or women inflate the extent and type of domestic assault. Third, it would be useful to further unpack the specialization and escalation parameters in an effort to determine if a particular stratifier leads to different estimates. For example, it may be that escalation/specialization vary according to the race of the suspect/victim, where the offenders were in the life-course when the study began (i.e., age), and/or according to whether some individuals have a higher likelihood of reporting domestic assault to the police. Fourth, our escalation analysis used a binary indicator of injury/no injury. Clearly, there are other methods of measuring injury such as an ordinal or even linear/Guttman metric and it would be useful to employ those approaches in subsequent research. ${ }^{9}$ Finally, bearing in mind that patterns of escalation/de-escalation have been rarely studied in criminal careers research (Piquero et al., 2003), it would be particularly useful to examine how patterns of offending vary along the seriousness dimension over time among domestic violence offenders.

In the end, this study provides us with a useful window on the mix and progression of criminal activities among domestic violence offenders in different parts of the United States. It tells us something about the generality of criminal behavior and the progression of domestic violence among offenders who abuse their partners. We hope it

\footnotetext{
${ }^{9}$ A reviewer raised an interesting point about whether the severity of the assaults escalate or de-escalate over time using the definition of injury employed in this study. For example, if the victim had a bruise in the initial, reported incident and was stabbed by the perpetrator three months later, the data would be recorded as an injury each time with no distinction as to severity or escalation. This is a good observation. Future research efforts should attempt to use different operational definitions of injury to determine the sensitivity of our results.
} 
This document is a research report submitted to the U.S. Department of Justice. This report has not been published by the Department. Opinions or points of view expressed are those of the author(s) and do not necessarily reflect the official position or policies of the U.S. Department of Justice.

will spur efforts to advance our understanding of theory and policy to address the criminal domestic violence problem. 
This document is a research report submitted to the U.S. Department of Justice. This report has not

been published by the Department. Opinions or points of view expressed are those of the author(s)

and do not necessarily reflect the official position or policies of the U.S. Department of Justice.

\section{References}

Blumstein, A., J. Cohen, J.A. Roth, and C. Visher. 1986. Criminal Careers and 'Career Criminals', Volume I. Washington, DC: National Academy Press.

Blumstein, A. J. Cohen, S. Das, and S.D. Moitra. 1988. Specialization and seriousness during adult criminal careers. Journal of Quantitative Criminology 4:303-345.

Brame, R. 2000. Investigating treatment effects in a domestic violence experiment with partially missing outcome data. Journal of Quantitative Criminology, 16:283-314.

Bureau of Justice Statistics. 2002. Criminal Victimization in the United States. Washington, DC: U.S. Department of Justice.

Chalk, R. and P.A. King. 1998. Violence in Families: Assessing Prevention and Treatment Programs. Washington, DC: National Academy Press.

Conaway, M. R. 1993. Non-ignorable non-response models for time-ordered categorical variables. Appl. Stat. 42: 105-115.

Dobash, R.E. and R.P. Dobash. 1992. Women, Violence, and Social Change. London: Routledge.

D’Unger, A., K. Land, P. McCall, and D.S. Nagin. 1998. How many latent classes of delinquent/criminal careers? Results from mixed Poisson regression analyses of the London, Philadelphia, and Racine cohort studies. American Journal of Sociology 103:1593-1630.

Elliott, D S. 1994. 1993 Presidential Address—Serious violent offenders: Onset, developmental course, and termination. Criminology 32:1-22.

Fagan, J.A. 1989. Cessation of family violence: Deterrence and dissuasion. In L. Ohlin and M. Tonry (eds.), Family Violence, Vol.11: Crime and Justice: An Annual Review of Research. Chicago, IL: University of Chicago Press.

Fagan, J.A., and A. Browne. 1994. Violence between spouses and intimates: Physical aggression between women and men in intimate relationships. In A.J. Reiss, Jr., and J.A. Roth (eds.), Understanding and Preventing Violence. Volume 3: Social Influences. Washington, DC: National Academy Press.

Fagan, J.A. and S. Wexler. 1987. Crime in the home and crime in the streets: The relation between family violence and stranger crime. Violence and Victims 2:5-21.

Fagan, J., D. Stewart, and K. Hansen. 1983. Violent men or violent husbands? 
This document is a research report submitted to the U.S. Department of Justice. This report has not

been published by the Department. Opinions or points of view expressed are those of the author(s)

and do not necessarily reflect the official position or policies of the U.S. Department of Justice.

Background factors and situational correlates of domestic and extra-domestic violence. In D. Finkelhor, R. Gelles, G. Hotaling, and M. Straus (eds.), The Dark Side of Families. Beverly Hills, CA: Sage Publications.

Fagan, J., E. Friedman, S. Wexler, and V. Lewis. 1984. The National Family Violence Evaluation: Final Report, Volume I: Analytic Findings. San Francisco, CA: URSA Institute.

Farrington, D.P. 1991. Childhood aggression and adult violence: Early precursors and later life outcomes. In D.J. Pepler and K.H. Rubin (eds.), The Development and Treatment of Childhood Aggression. Hillsdale, NJ: Erlbaum.

Feld, S.L. and M.A. Straus. 1989. Escalation and desistance of wife assault in marriage. Criminology 27:141-161.

Garner, J., J. Fagan, and C. Maxwell. 1995. Published findings from the spouse assault replication program: A critical review. Journal of Quantitative Criminology 11:3-28.

Gelles, R.J. and M.A. Strauss. 1979. Determinants of violence in the family: Toward a theoretical integration. In W. Burr, R. Hill, F.I. Nye, and I.L. Triss (eds.), Contemporary Theories About the Family. New York: Free Press.

Gelles, R.J. and M.A. Strauss. 1988. Intimate Violence. New York: Simon and Schuster.

Gottfredson, M. and T. Hirschi. 1990. A General Theory of Crime. Stanford, CA:

Stanford University Press.

Holtzworth-Munroe, A., J.C. Meehanm K. Herron, U. Rehman, and G.L. Stuart. 2000. Testing the Holtzworth-Munroe and Stuart (1994) batterer typology. Journal of Consulting and Clinical Psychology 68:1000-1019.

Iversen, G.R. 1984. Bayesian Statistical Inference. Thousand Oaks, CA: Sage Publications.

Johnson, M.P. 1995. Patriarchal terrorism and common couple violence: Two forms of violence against women. Journal of Marriage and the Family 57:283-294.

Kadane, J. B. 1985. Is victimization chronic? A Bayesian analysis of multinomial missing data. J. Econometr. 29: 47-67.

Koss, M.P., L.A. Goodman, A. Browne, L.F. Fitzgerald, G.P. Keita, and N.F. Russo. 1994. No Safe Haven: Male Violence Against Women at Home, at Work, and in the Community. Washington, DC: American Psychological Association.

Laub, J.H. and R.J. Sampson. 2001. Understanding desistance from crime. In Michael 
This document is a research report submitted to the U.S. Department of Justice. This report has not

been published by the Department. Opinions or points of view expressed are those of the author(s)

and do not necessarily reflect the official position or policies of the U.S. Department of Justice.

Tonry (ed.), Crime and Justice: An Annual Review of Research. Chicago: University of Chicago Press.

Le Blanc, M., and M. Fréchette. 1989. Male Criminal Activity from Childhood through Youth: Multilevel and Developmental Perspectives. New York: Springer-Verlag.

Lynam, D., T.E. Moffitt, and A.R. Piquero. 2004. Specialization and the propensity to violence: Support from self-reports but not official records. Journal of Contemporary Criminal Justice 20:215-228.

Maxwell, C., J. Garner, and J. Fagan. 2002. The preventive effects of arrest on intimate partner violence: Research, policy, and theory. Criminology and Public Policy, 2:51-80.

McDermott, S. and D.S. Nagin. 2001. Same or different? Comparing offender groups and covariates over time. Sociological Methods and Research 29:282-318.

Moffitt, T.E. 1993. Adolescence-limited and life-course persistent antisocial behavior: a developmental taxonomy. Psychological Review, 100, 674-701.

Moffitt, T.E., R.F. Krueger, A. Caspi, and J. Fagan. 2000. Partner abuse and general crime: How are they the same? How are they different? Criminology 38:201-235.

Nagin, D.S. and K. Land. 1993. Age, criminal careers, and population heterogeneity: specification and estimation of a nonparametric, mixed poisson model. Criminology 31:327-362.

Pagelow, M.D. 1984. Family Violence. New York, NY: Praeger.

Piquero, A.R. 2000. Frequency, specialization, and violence in offending careers. Journal of Research in Crime and Delinquency 37:392-418.

Piquero, A.R., D.P. Farrington, and A. Blumstein. 2003. The criminal career paradigm. In Crime and Justice: A Review of Research, Volume 30, edited by Michael Tonry. Chicago: University of Chicago Press.

Reiss, A.J. and J.A. Roth. 1993. Understanding and Preventing Violence. Washington, DC: National Academy Press.

Rennison, C. M. 2000. Intimate Partner Violence. Bureau of Justice Statistics: U.S. Department of Justice. Washington, DC.

Rojek, D.G. and M.L. Erikson. 1982. Delinquent careers: A test of the career escalation model. Criminology 20:5-28. 
This document is a research report submitted to the U.S. Department of Justice. This report has not

been published by the Department. Opinions or points of view expressed are those of the author(s)

and do not necessarily reflect the official position or policies of the U.S. Department of Justice.

Sampson, R.J. and J.H. Laub. 1993. Crime in the Making. Cambridge: Harvard University Press.

Saphire, D.G. 1984. Estimation of victimization prevalence using data from the National Crime Survey. Lecture Notes in Statistics, 23, Springer-Verlag, New York.

Sherman, Lawrence W. 1992. Policing Domestic Violence. Free Press: New York, NY.

Sherman, L.W. and R.A. Berk. 1984. The specific deterrent effects of arrest for domestic assault. American Sociological Review 49:261-272.

Shields, N., G.J. McCall, and C.R. Hanneke. 1988. Patterns of family and non-family violence: Violent husbands and violent men. Violence and Victims 3:83-98.

Stasny, E.A. 1990. Symmetry in flows among reported victimization classifications with nonresponse. Survey Method. 16:305-330.

Stasny, E.A. 1991. Hierarchical models for the probabilities of a survey classification and nonresponse: An example from the National Crime Survey. J. Am. Stat. Assoc. 86:296303.

Tjaden, Patricia and Nancy Thoennes. 2000. Extent, Nature, and Consequences of Intimate Partner Violence: Findings from the National Violence Against Women Survey. National Institute of Justice: U.S. Department of Justice. Washington, DC.

Walker, L.E. 1984. The Battered Woman Syndrome. New York, NY: Springer. 
This document is a research report submitted to the U.S. Department of Justice. This report has not been published by the Department. Opinions or points of view expressed are those of the author(s) and do not necessarily reflect the official position or policies of the U.S. Department of Justice.

\section{List of Tables}

Table 1: Summary of Specialization Results by Site

Table 2: Summary of Escalation Results by Site

Table 3: Summary of De-Escalation Results by Site 
This document is a research report submitted to the U.S. Department of Justice. This report has not

been published by the Department. Opinions or points of view expressed are those of the author(s)

and do not necessarily reflect the official position or policies of the U.S. Department of Justice.

\section{List of Figures}

Figure 1: Posterior Distribution of Violent Specialization Parameter - Charlotte SARP Data.

Figure 2: Posterior Distribution of Violent Specialization Parameter - Colorado Spring SARP Data.

Figure 3: Posterior Distribution of Violent Specialization Parameter - Milwaukee SARP Data.

Figure 4: Posterior Distribution of Violent Specialization Parameter - Omaha SARP Data - Pre-Presenting Incident Arrests Only.

Figure 5: Posterior Distribution of Violent Specialization Parameter - Omaha SARP Data - All Arrests Through 12 Months After Presenting Incident.

Figure 6: Full Posterior Distribution of Specialization Parameter by Site.

Figure 7: Escalation Analysis from Initial and Six-Month Interviews - Charlotte SARP Data.

Figure 8: De-Escalation Analysis from Initial and Six-Month Interviews - Charlotte SARP Data.

Figure 9: Escalation Analysis from Initial and Six-Month Interviews - Miami-Dade SARP Data.

Figure 10: De-Escalation Analysis from Initial and Six-Month Interviews - Miami-Dade SARP Data.

Figure 11: Escalation Analysis from Initial and Six-Month Interviews - Milwaukee SARP Data.

Figure 12: De-Escalation Analysis from Initial and Six-Month Interviews - Milwaukee SARP Data.

Figure 13: Escalation Analysis from Six- and Twelve-Month Interviews - Omaha SARP Data.

Figure 14: De-Escalation Analysis from Six- and Twelve-Month Interviews - Omaha SARP Data. 
Table 1

Summary of Specialization Results by Site

\begin{tabular}{lrrrrrrrr}
\hline Site & $N=$ & $N_{\mathrm{p}}$ & $N_{\mathrm{p}} / N$ & $n_{v}$ & $n_{v}{ }^{\prime}$ & $s_{v}$ & $S_{v L}$ & $S_{v H}$ \\
\hline & & & & & & & & \\
Charlotte & 650 & 111 & 0.171 & 14 & 97 & 0.126 & 0.077 & 0.200 \\
Colorado Springs & 1,525 & 624 & 0.409 & 41 & 583 & 0.066 & 0.048 & 0.087 \\
Milwaukee & 1,124 & 657 & 0.585 & 154 & 503 & 0.234 & 0.203 & 0.268 \\
Omaha \#1 & 577 & 363 & 0.629 & 16 & 347 & 0.044 & 0.027 & 0.070 \\
Omaha \#2 & 577 & 463 & 0.802 & 64 & 399 & 0.138 & 0.109 & 0.172 \\
& & & & & & & & \\
\hline
\end{tabular}

\section{Notes:}

$N=$ Analysis Sample Size

$N_{\mathrm{p}}=$ Number of Individuals with Arrest Record

$N_{\mathrm{p}}^{\mathrm{p}} / N=$ Proportion of Sample With Arrest Record

$n_{\mathrm{v}}{ }_{\mathrm{v}}=$ Number of Violent Specialists

$n_{\mathrm{v}}{ }^{\prime}=N_{\mathrm{p}}-n_{\mathrm{v}}$

$s_{\mathrm{v}}=n_{\mathrm{v}} / N_{\mathrm{p}}$

$s_{\mathrm{vL}}=$ Lower Bound of 95\% Posterior Probability Interval for $s_{\mathrm{v}}$

$s_{\mathrm{vH}}=$ Upper Bound of 95\% Posterior Probability Interval for $s_{\mathrm{v}}$

Omaha \#1 refers to officially recorded charges prior to presenting incident; Omaha \#2 refers to offenses both before and after the presenting incident. 
Table 2

Summary of Escalation Results by Site

\begin{tabular}{lrrrrrrrr}
\hline Site/Interview & $N_{\mathrm{i}}{ }^{\prime}$ & $N_{\mathrm{i} 1}{ }^{\prime}$ & $N_{\mathrm{i} 1}{ }^{\prime} / N_{\mathrm{i}}{ }^{\prime}$ & $n_{e}$ & $n_{e}{ }^{\prime}$ & $e$ & $e_{L}$ & $e_{H}$ \\
\hline Charlotte (I) & & & & & & & & \\
Charlotte (6) & 196 & 26 & 0.133 & 18 & 8 & 0.692 & 0.498 & 0.834 \\
Miami-Dade (I) & 148 & 43 & 0.291 & 36 & 7 & 0.837 & 0.699 & 0.918 \\
Miami-Dade (6) & 117 & 12 & 0.063 & 2 & 10 & 0.167 & 0.050 & 0.454 \\
Milwaukee (I) & 170 & 47 & 0.197 & 7 & 16 & 0.304 & 0.156 & 0.511 \\
Milwaukee (6) & 142 & 62 & 0.437 & 22 & 40 & 0.355 & 0.247 & 0.479 \\
Omaha (6) & 103 & 51 & 0.495 & 20 & 31 & 0.392 & 0.270 & 0.529 \\
Omaha (12) & 99 & 60 & 0.606 & 26 & 34 & 0.433 & 0.315 & 0.559 \\
& & & & & & & & \\
\hline
\end{tabular}

Notes:

(I) = Initial interview

(6) = 6-Month interview

$(12)=12-$ Month interview

$N_{\mathrm{i}}{ }^{\prime}=$ Number of Interviewed Victims Without Injury at Presenting Incident

$N_{\mathrm{i} 1}{ }^{\prime}=$ Number of Individuals in $N_{\mathrm{i}}$ ' Victimized Between Presenting Incident and Interview

$N_{\mathrm{i} 1}{ }^{\prime} / N_{\mathrm{i}}{ }^{\prime}=$ Proportion of $\mathrm{N}_{\mathrm{i}}$ ' With New Victimization Between Presenting Incident and Interview

$n_{\mathrm{e}}=$ Number of Victims Reporting an Injury After Presenting Incident (Escalations)

$n_{\mathrm{e}}{ }^{\mathrm{e}}=N_{\mathrm{i} 1}{ }^{\prime}-n_{\mathrm{e}}$ (Number of Stable Non-Injury Victims)

$e=n_{\mathrm{e}} / N_{\mathrm{i} 1}$ ' (Escalation Parameter)

$e_{\mathrm{L}}=$ Lower Bound of 95\% Posterior Probability Interval for $e$

$e_{\mathrm{H}}=$ Upper Bound of 95\% Posterior Probability Interval for $e$ 
Table 3

Summary of De-escalation Results by Site

\begin{tabular}{lrrrrrrrr}
\hline Site/Interview & $N_{\mathrm{i}}$ & $N_{\mathrm{i} 1}$ & $N_{\mathrm{i} 1} / N_{\mathrm{i}}$ & $n_{d}$ & $n_{d}{ }^{\prime}$ & $d$ & $d_{L}$ & $d_{H}$ \\
& & & & & & & & \\
Charlotte (I) & 219 & 52 & 0.237 & 7 & 45 & 0.135 & 0.067 & 0.253 \\
Charlotte (6) & 172 & 77 & 0.448 & 6 & 71 & 0.078 & 0.037 & 0.160 \\
Miami-Dade (I) & 403 & 72 & 0.179 & 30 & 42 & 0.417 & 0.309 & 0.532 \\
Miami-Dade (6) & 254 & 75 & 0.295 & 33 & 42 & 0.440 & 0.333 & 0.552 \\
Milwaukee (I) & 530 & 126 & 0.238 & 91 & 35 & 0.722 & 0.646 & 0.799 \\
Milwaukee (6) & 457 & 212 & 0.464 & 81 & 131 & 0.382 & 0.319 & 0.449 \\
Omaha (6) & 335 & 202 & 0.603 & 115 & 87 & 0.569 & 0.500 & 0.635 \\
Omaha (12) & 317 & 221 & 0.697 & 111 & 110 & 0.502 & 0.436 & 0.567 \\
& & & & & & & & \\
\hline
\end{tabular}

Notes:

(I) = Initial interview

(6) = 6-Month interview

$(12)=12$-Month interview

$N_{\mathrm{i}}=$ Number of Interviewed Victims With Injury at Presenting Incident

$N_{\mathrm{i} 1}=$ Number of Individuals in $N_{\mathrm{i}}$ Victimized Between Presenting Incident and Interview

$N_{\mathrm{i} 1} / N_{\mathrm{i}}=$ Proportion of $N_{\mathrm{i}}$ With New Victimization Between Presenting Incident and Interview

$n_{\mathrm{d}}=$ Number of Victims Reporting No Injury After Presenting Incident (De-escalations)

$n_{\mathrm{d}}{ }^{\prime}=N_{\mathrm{i} 1}-n_{\mathrm{d}}$ (Number of Stable Injury Victims)

$d=n_{\mathrm{d}} / N_{\text {i1 }}$ (De-escalation Parameter)

$d_{\mathrm{L}}=$ Lower Bound of 95\% Posterior Probability Interval for $d$

$d_{\mathrm{H}}=$ Upper Bound of 95\% Posterior Probability Interval for $d$ 
This document is a research report submitted to the U.S. Department of Justice. This report has not been published by the Department. Opinions or points of view expressed are those of the author(s) and do not necessarily reflect the official position or policies of the U.S. Department of Justice.

Figure 1

Posterior Distribution of Violent Specialization Parameter - Charlotte SARP Data

\section{Posterior Distribution of Specialization Parameter}

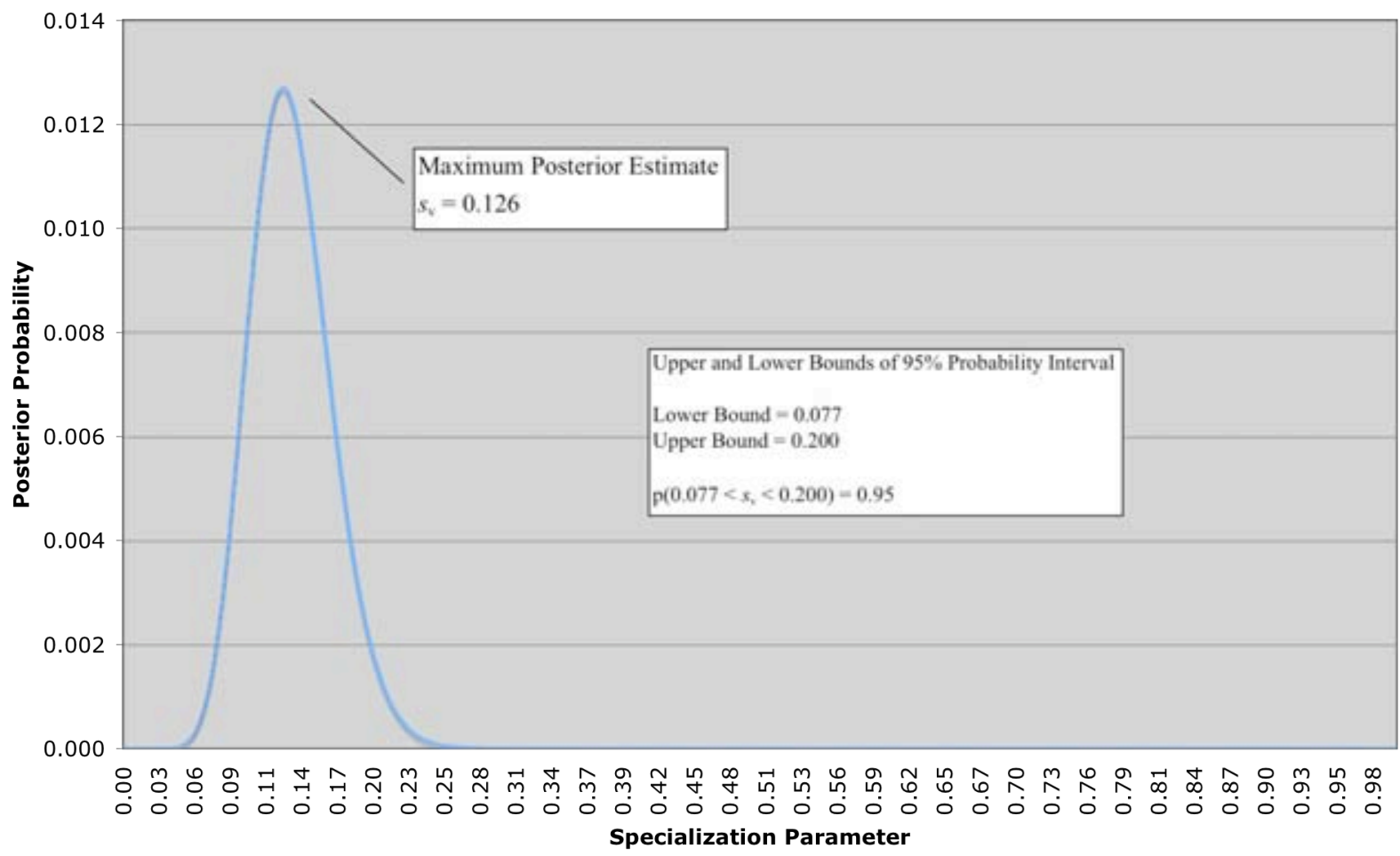


This document is a research report submitted to the U.S. Department of Justice. This report has not been published by the Department. Opinions or points of view expressed are those of the author(s) and do not necessarily reflect the official position or policies of the U.S. Department of Justice.

Figure 2

Posterior Distribution of Violent Specialization Parameter - Colorado Springs SARP Data

Posterior Distribution of Specialization Parameter

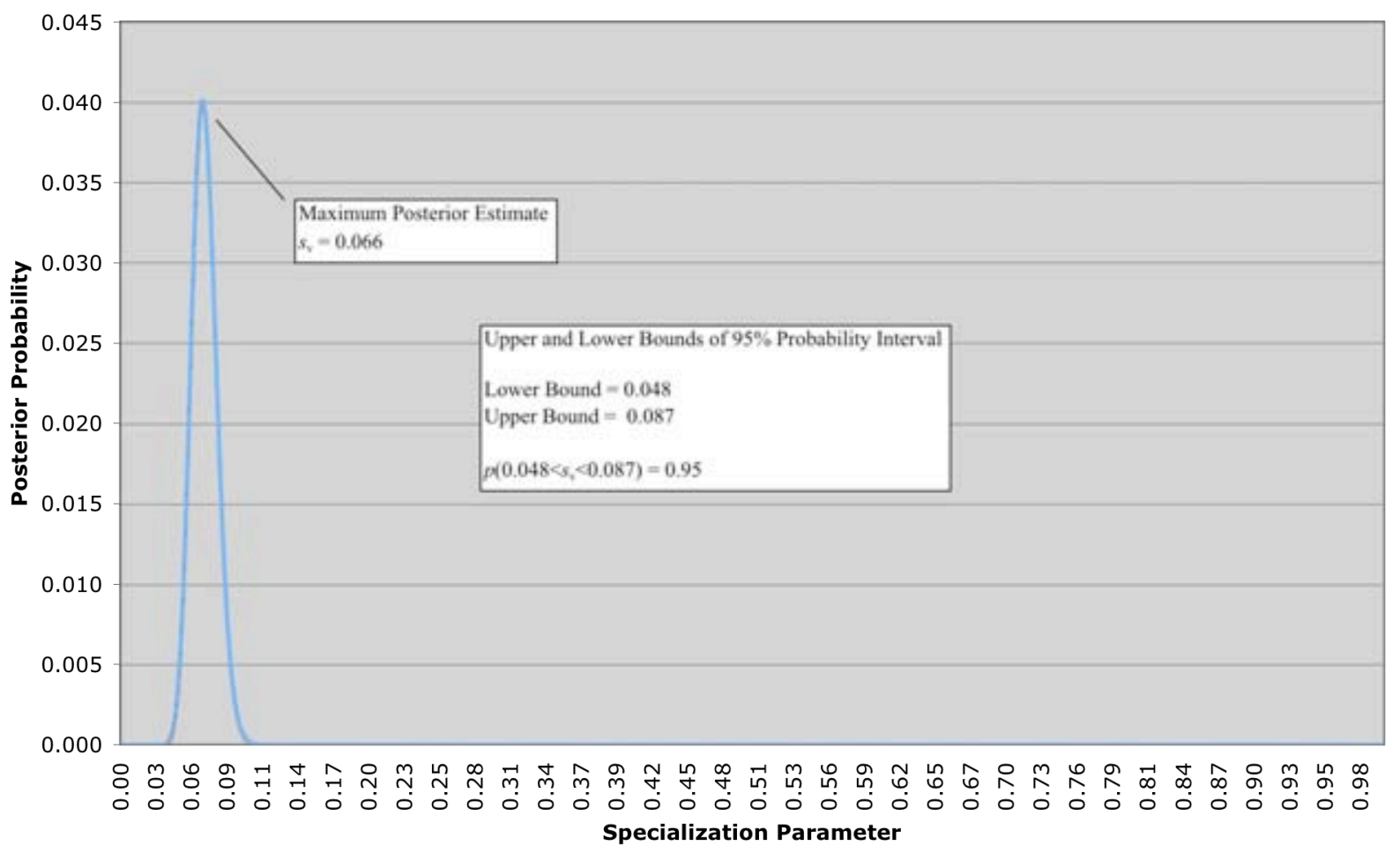


This document is a research report submitted to the U.S. Department of Justice. This report has not been published by the Department. Opinions or points of view expressed are those of the author(s) and do not necessarily reflect the official position or policies of the U.S. Department of Justice.

Figure 3

Posterior Distribution of Violent Specialization Parameter - Milwaukee SARP Data

Posterior Distribution of Specialization Parameter

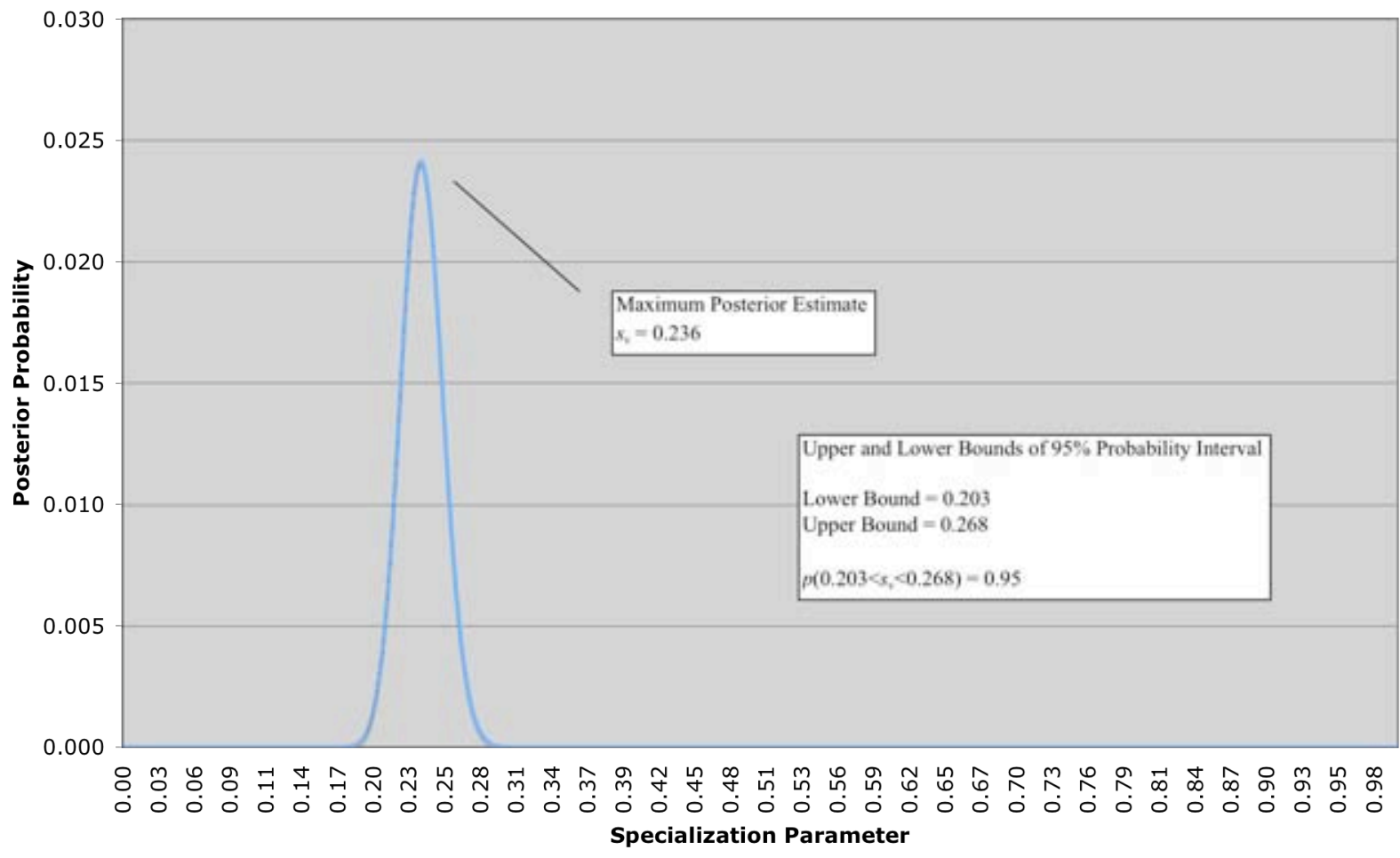


This document is a research report submitted to the U.S. Department of Justice. This report has not been published by the Department. Opinions or points of view expressed are those of the author(s) and do not necessarily reflect the official position or policies of the U.S. Department of Justice.

Figure 4

Posterior Distribution of Violent Specialization Parameter in Omaha SARP Data - PrePresenting Incident Arrests Only

\section{Posterior Distribution of Specialization Parameter}

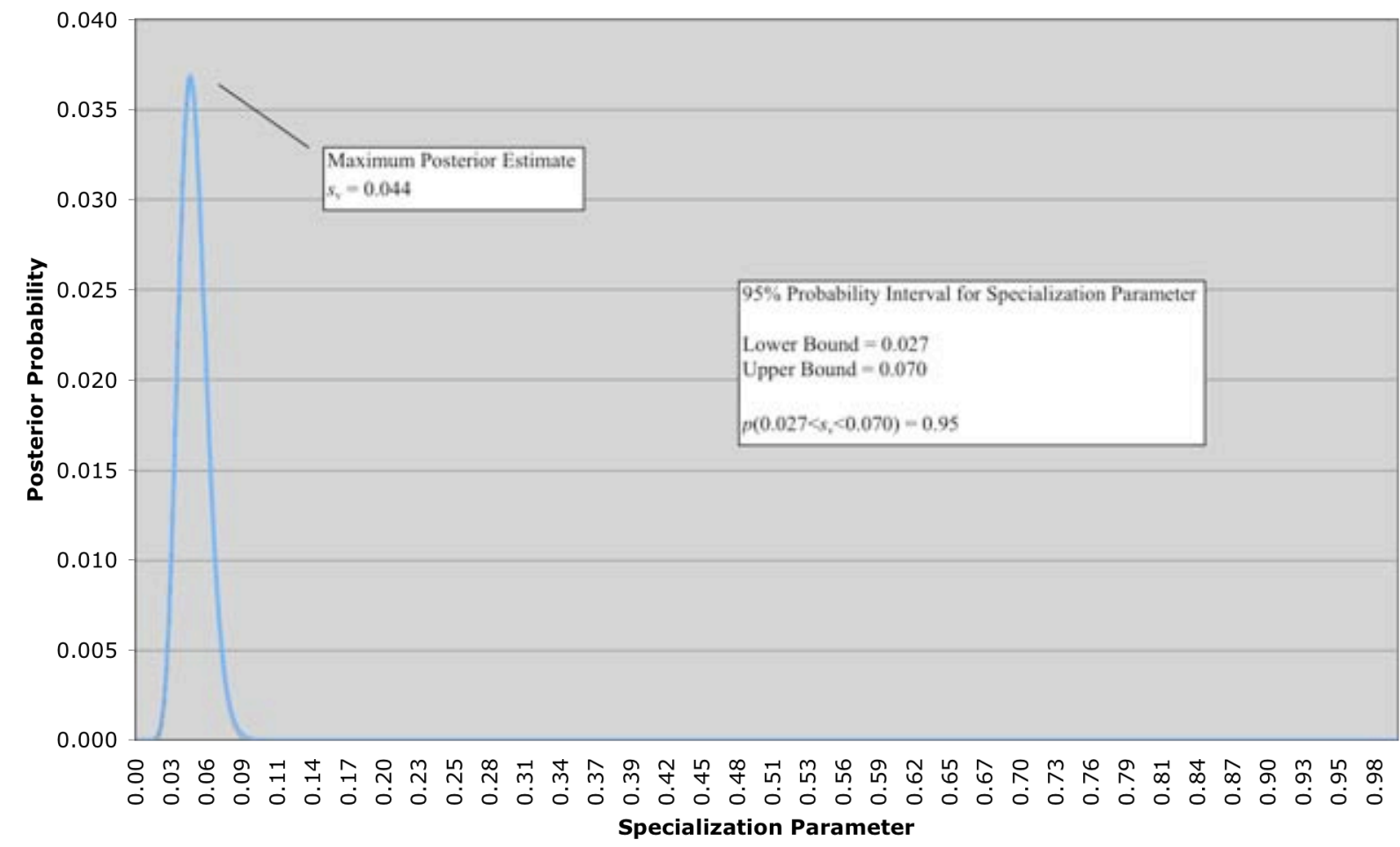


This document is a research report submitted to the U.S. Department of Justice. This report has not been published by the Department. Opinions or points of view expressed are those of the author(s) and do not necessarily reflect the official position or policies of the U.S. Department of Justice.

Figure 5

Posterior Distribution of Violent Specialization Parameter in Omaha SARP Data - All Arrests Through 12 Months After Presenting Incident

Posterior Distribution of Specialization Parameter

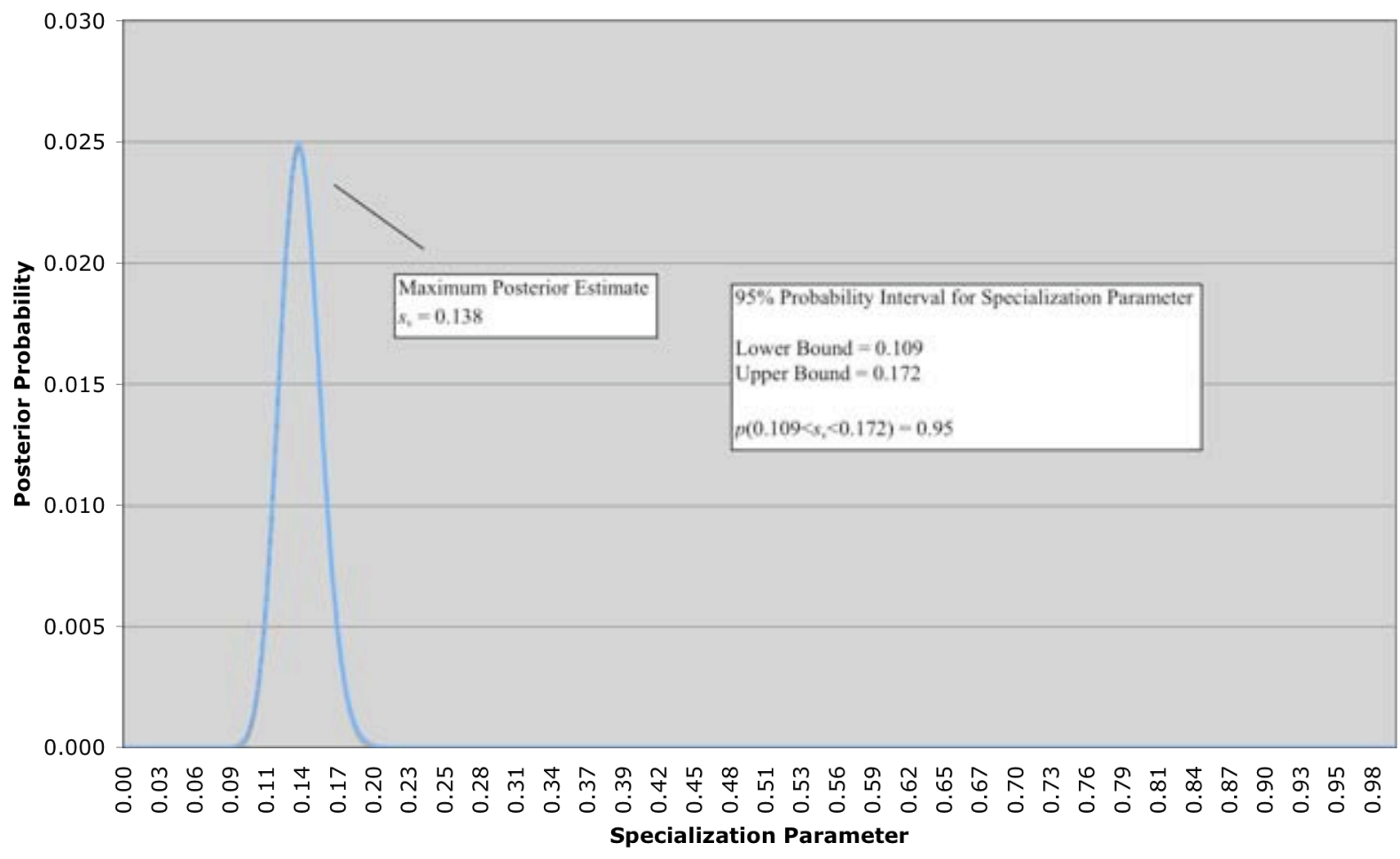


This document is a research report submitted to the U.S. Department of Justice. This report has not been published by the Department. Opinions or points of view expressed are those of the author(s) and do not necessarily reflect the official position or policies of the U.S. Department of Justice.

Figure 6

Full Posterior Distribution of Specialization Parameter by Site

Posterior Distribution of Specialization Parameter by Site

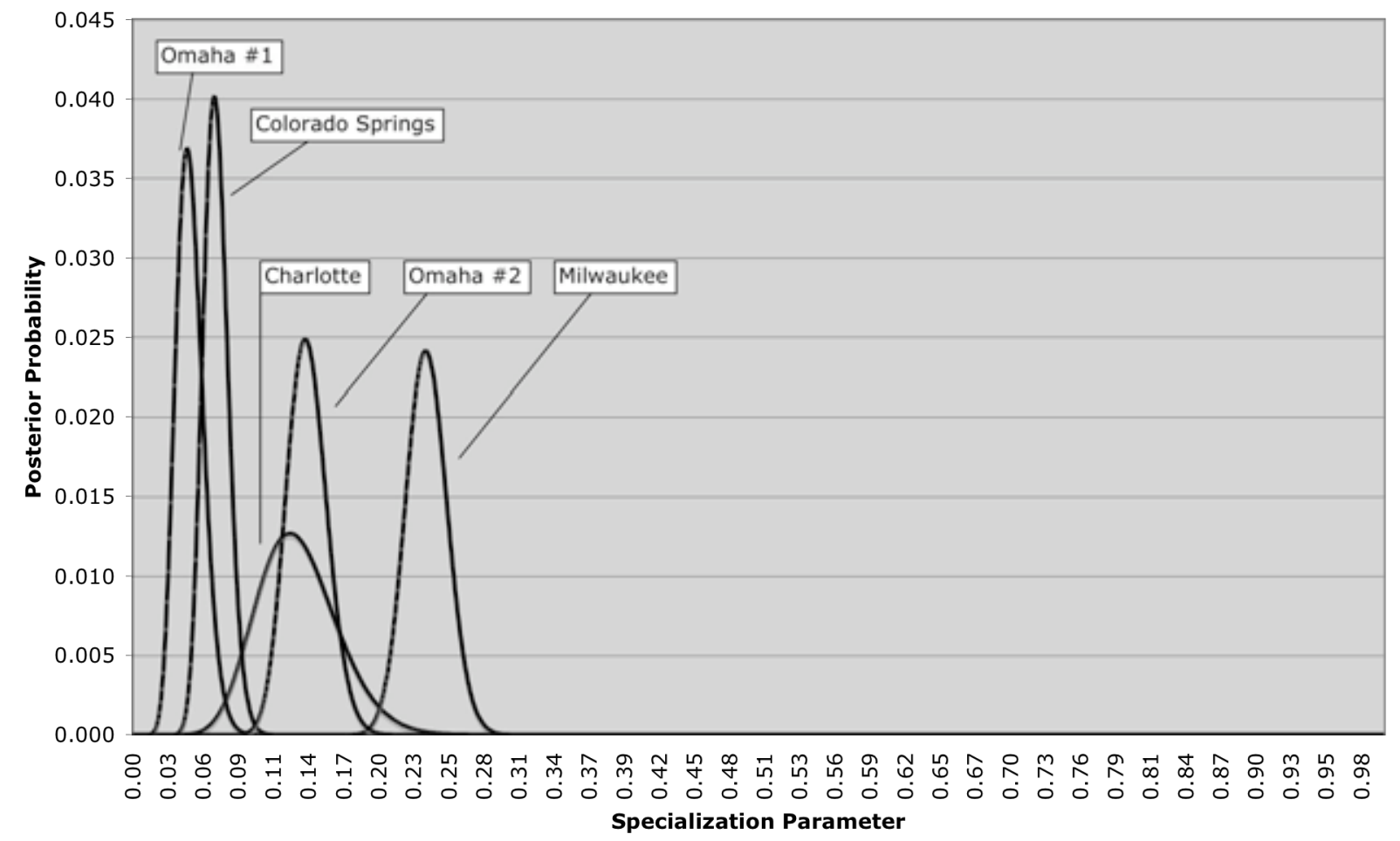


This document is a research report submitted to the U.S. Department of Justice. This report has not been published by the Department. Opinions or points of view expressed are those of the author(s) and do not necessarily reflect the official position or policies of the U.S. Department of Justice.

Figure 7

Escalation Analysis from Initial and Six-Month Interviews - Charlotte SARP Data

\section{Posterior Distribution of Escalation Parameter}

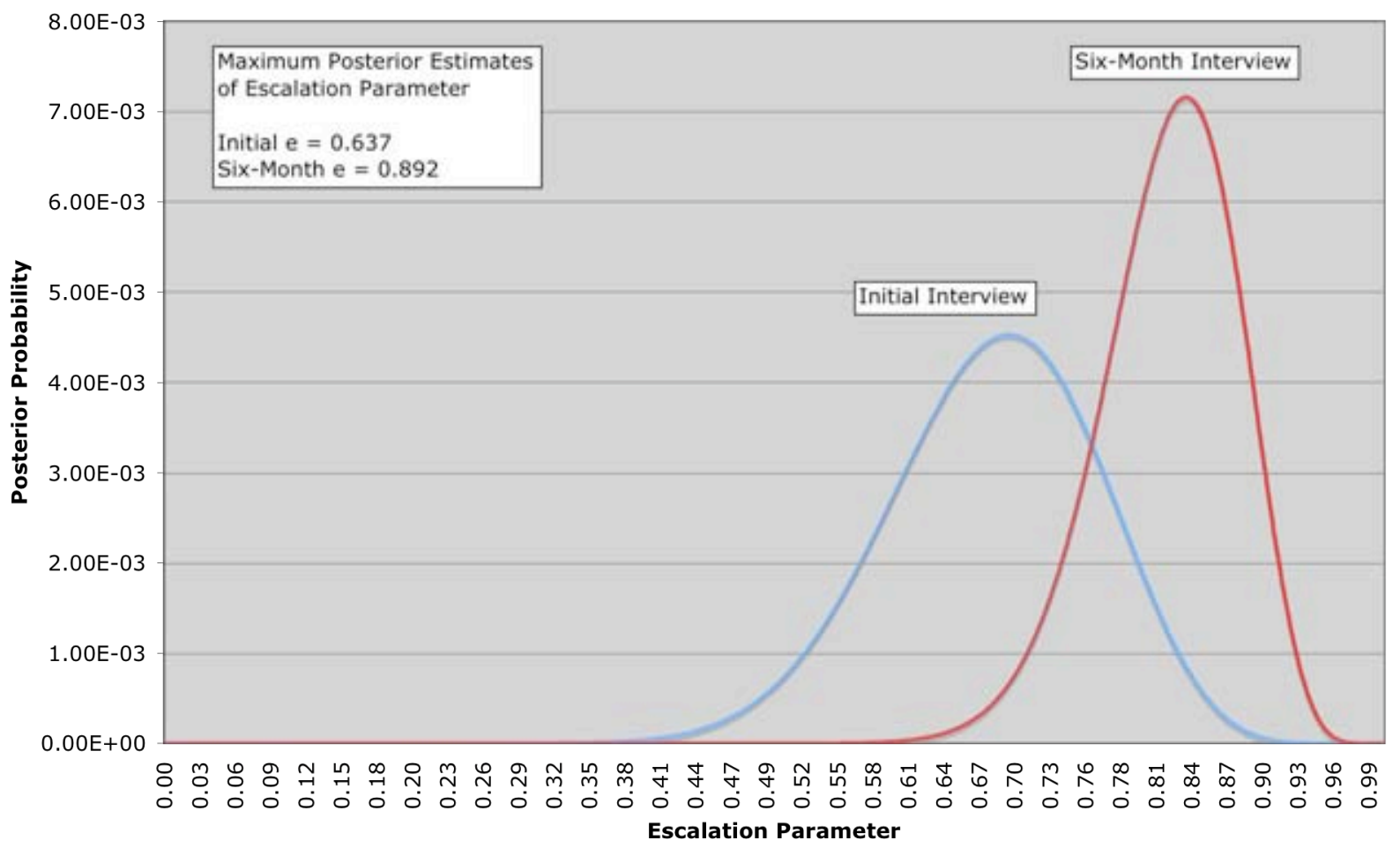


This document is a research report submitted to the U.S. Department of Justice. This report has not been published by the Department. Opinions or points of view expressed are those of the author(s) and do not necessarily reflect the official position or policies of the U.S. Department of Justice.

Figure 8

De-escalation Analysis from Initial and Six-Month Interviews - Charlotte SARP Data

Posterior Distribution of De-escalation Parameter

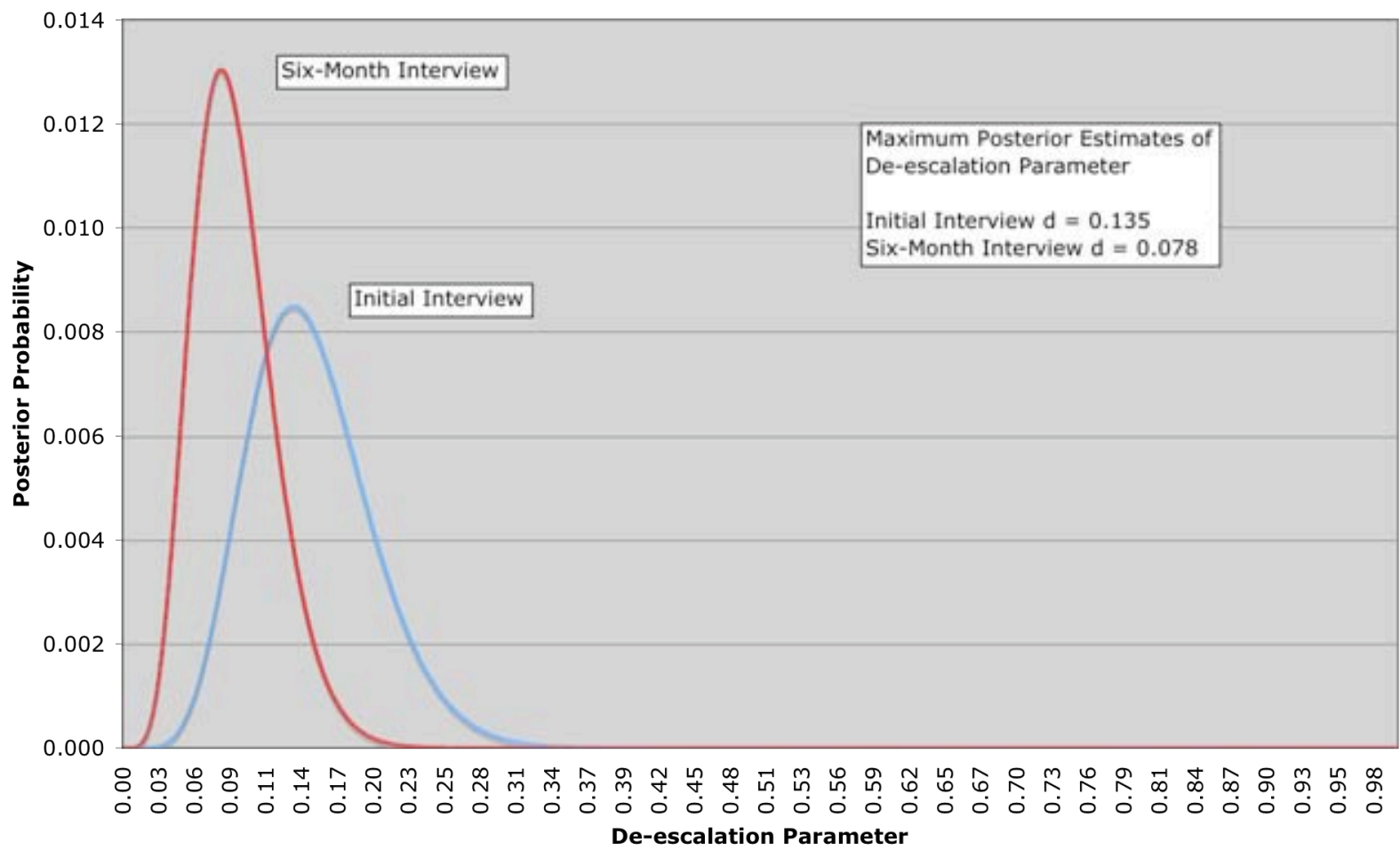


This document is a research report submitted to the U.S. Department of Justice. This report has not been published by the Department. Opinions or points of view expressed are those of the author(s) and do not necessarily reflect the official position or policies of the U.S. Department of Justice.

Figure 9

Escalation Analysis from Initial and Six-Month Interviews -Miami-Dade SARP Data

\section{Posterior Distribution of Escalation Parameter}

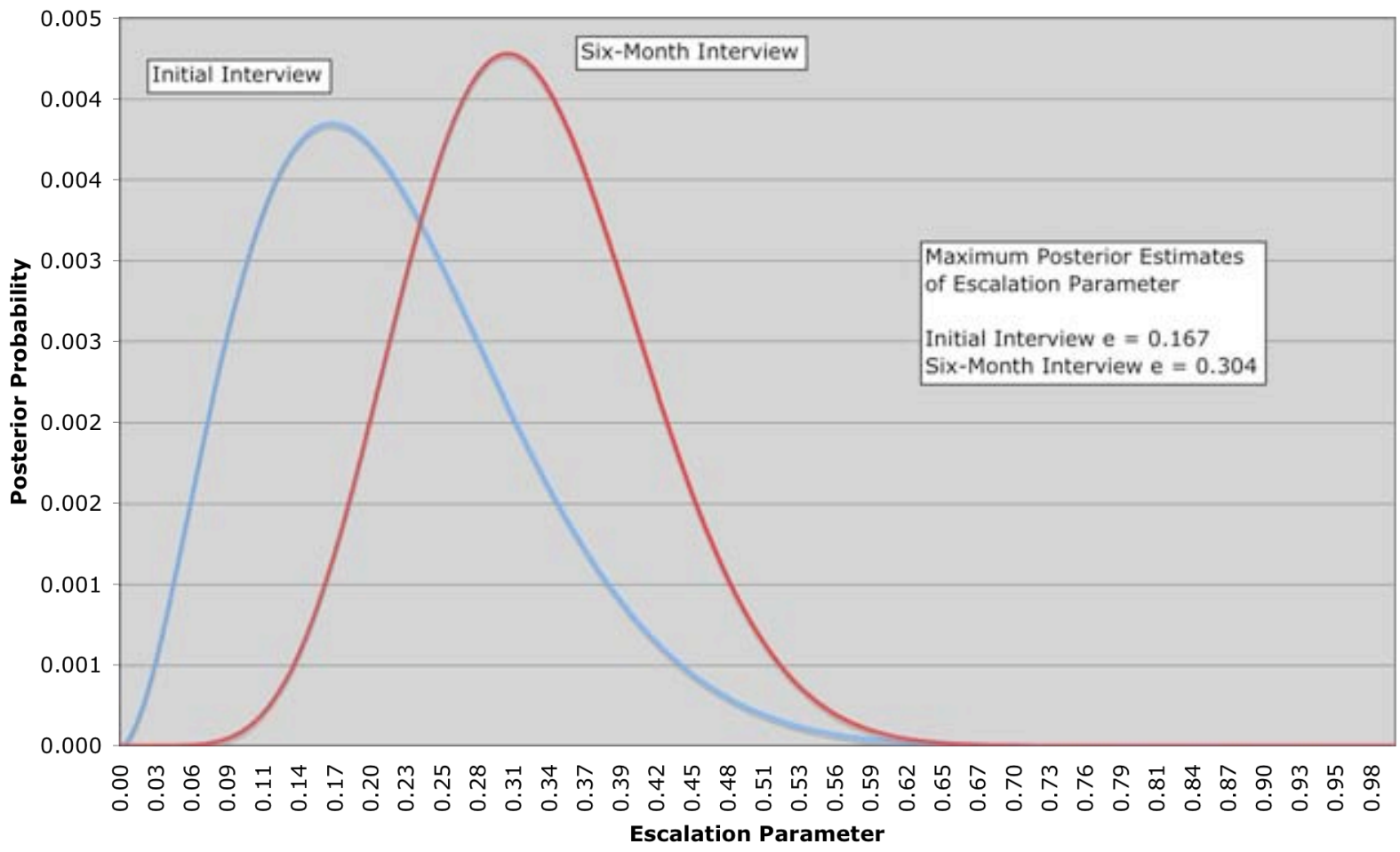


This document is a research report submitted to the U.S. Department of Justice. This report has not been published by the Department. Opinions or points of view expressed are those of the author(s) and do not necessarily reflect the official position or policies of the U.S. Department of Justice.

Figure 10

De-escalation Analysis from Initial and Six-Month Interviews - Miami-Dade SARP Data

\section{Posterior Distribution of De-escalation Parameter}

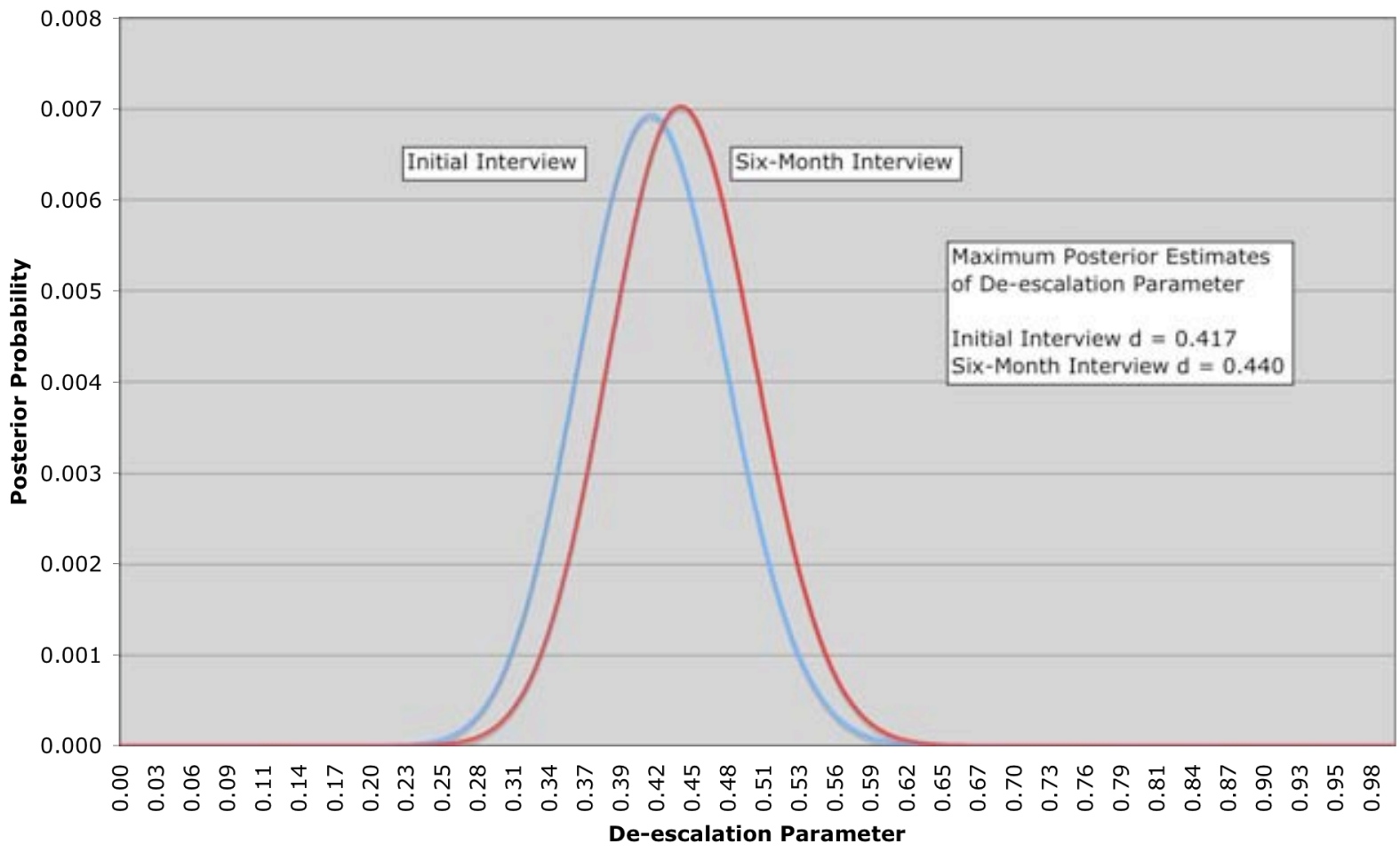


This document is a research report submitted to the U.S. Department of Justice. This report has not been published by the Department. Opinions or points of view expressed are those of the author(s) and do not necessarily reflect the official position or policies of the U.S. Department of Justice.

Figure 11

Escalation Analysis from Initial and Six-Month Interviews -Milwaukee SARP Data

\section{Posterior Distribution of Escalation Parameter}

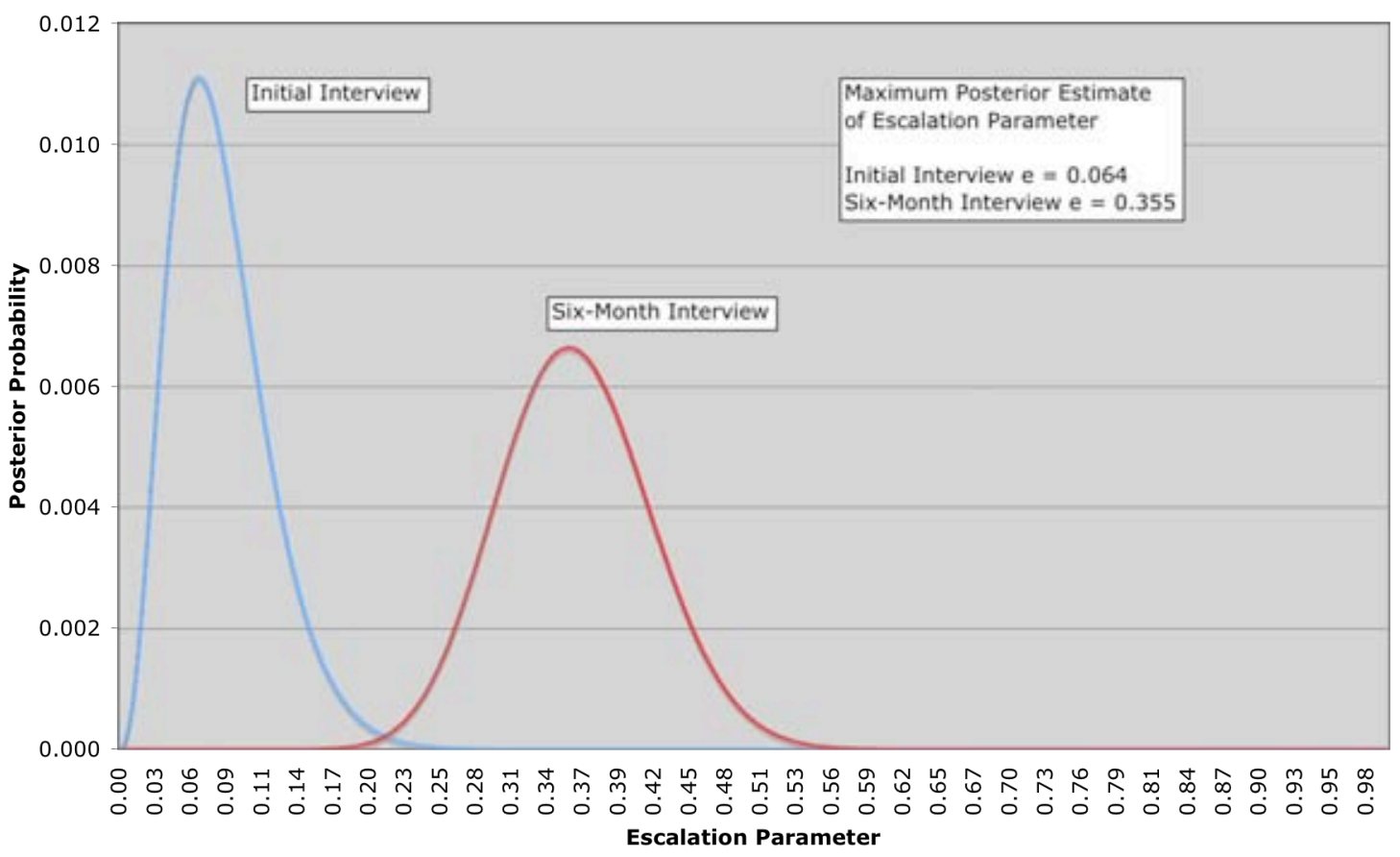


This document is a research report submitted to the U.S. Department of Justice. This report has not been published by the Department. Opinions or points of view expressed are those of the author(s) and do not necessarily reflect the official position or policies of the U.S. Department of Justice.

Figure 12

De-escalation Analysis from Initial and Six-Month Interviews - Milwaukee SARP Data

Posterior Distribution of De-escalation Parameter

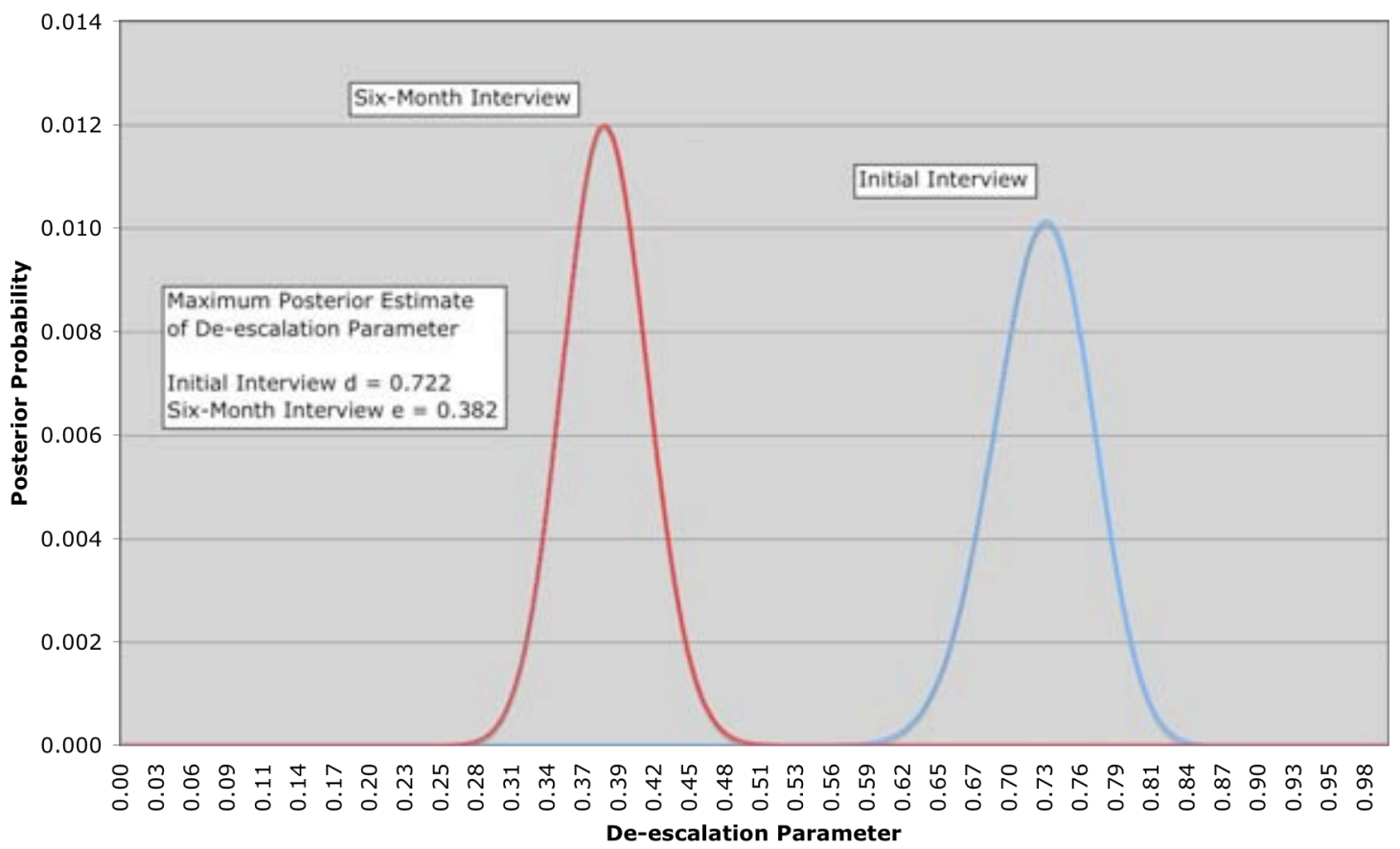


This document is a research report submitted to the U.S. Department of Justice. This report has not been published by the Department. Opinions or points of view expressed are those of the author(s) and do not necessarily reflect the official position or policies of the U.S. Department of Justice.

Figure 13

Escalation Analysis from Six- and Twelve-Month Interviews - Omaha SARP Data

\section{Posterior Distribution of Escalation Parameter}

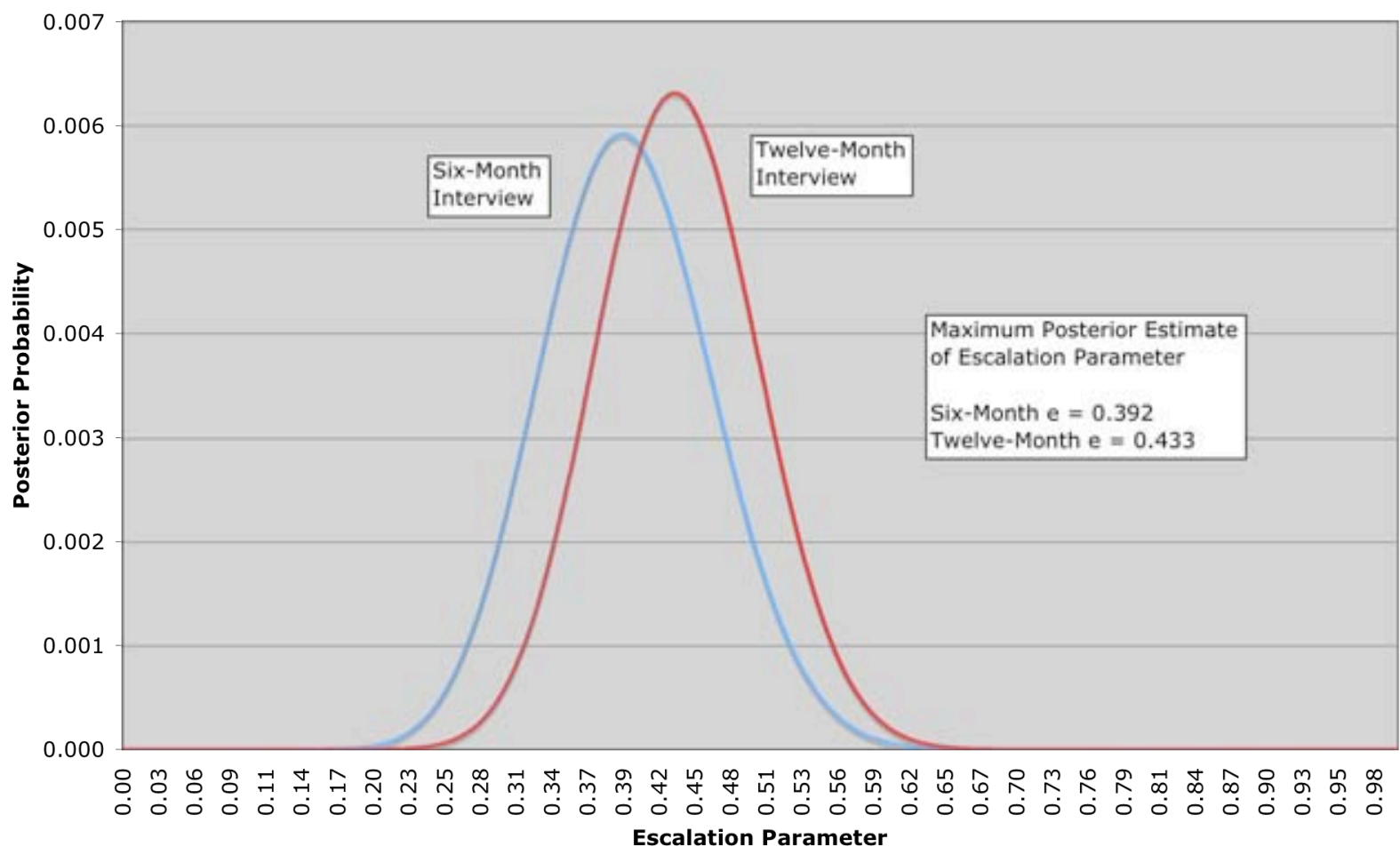


This document is a research report submitted to the U.S. Department of Justice. This report has not been published by the Department. Opinions or points of view expressed are those of the author(s) and do not necessarily reflect the official position or policies of the U.S. Department of Justice.

Figure 14

De-escalation Analysis from Six- and Twelve-Month Interviews - Omaha SARP Data

\section{Posterior Distribution of De-escalation Parameter}

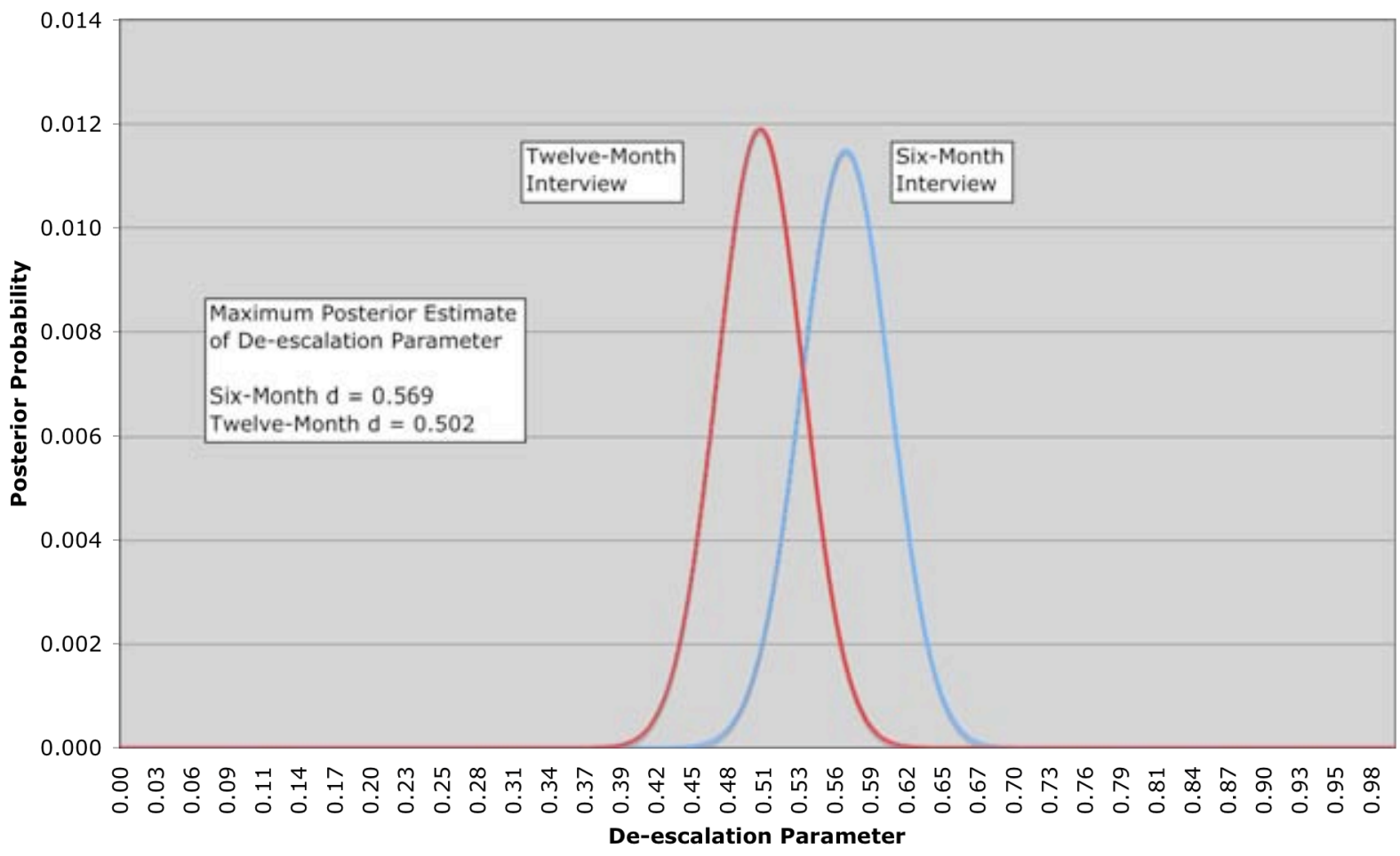

